\title{
A chemical probe technique for the determination of reactive halogen species in aqueous solution: Part 2 - chloride solutions and mixed bromide/chloride solutions
}

\author{
C. Anastasio ${ }^{1}$ and B. M. Matthew ${ }^{1, *}$ \\ ${ }^{1}$ Atmospheric Science Program, Department of Land, Air \& Water Resources, University of California, Davis, USA \\ *now at: Hach Company, Loveland, Colorado, USA
}

Received: 16 November 2005 - Published in Atmos. Chem. Phys. Discuss.: 2 February 2006

Revised: 27 April 2006 - Accepted: 11 May 2006 - Published: 29 June 2006

\begin{abstract}
Although reactive halogen species $\left(\mathrm{X}^{*}=\mathrm{X}^{\bullet}, \mathrm{X}_{2}^{-}\right.$, $\mathrm{X}_{2}$ and $\mathrm{HOX}$, where $\mathrm{X}=\mathrm{Br}, \mathrm{Cl}$, or I) are important environmental oxidants, relatively little is known about their kinetics in condensed phases such as seawater and sea-salt particles. Here we describe a new technique to determine reactive chlorine and bromine species in aqueous solutions by using allyl alcohol $\left(\mathrm{CH}_{2}=\mathrm{CHCH}_{2} \mathrm{OH}\right)$ as a chemical probe. This probe is combined with competition kinetics in order to determine steady state concentrations of $\mathrm{X}^{*}(\mathrm{aq})$. In some cases the technique also can be used to determine the rates of formation and lifetimes of $X^{*}$ in aqueous solution. In a companion paper we reported the results of our method development for aqueous solutions containing only bromide $\left(\mathrm{Br}^{-}\right)$. In this paper, we discuss method development for solutions containing chloride $\left(\mathrm{Cl}^{-}\right)$alone, and for solutions containing both bromide and chloride.
\end{abstract}

\section{Introduction}

As discussed in detail in the companion paper to this work (Matthew and Anastasio, 2006, hereafter referred to as "Part 1"), aqueous and gaseous reactive halogen species $\left(\mathrm{X}^{*}=\mathrm{X}^{\bullet}, \mathrm{X}_{2}^{-}, \mathrm{XO}^{\bullet}, \mathrm{X}_{2}\right.$ and $\mathrm{HOX}$, where $\mathrm{X}=\mathrm{Br}, \mathrm{Cl}$, or I) play important roles in the chemistry of marine regions. To further our understanding of aqueous-phase halide chemistry, and its links to the release of reactive gas-phase halogens, we have developed a chemical probe technique to detect and measure reactive halogen species in aqueous solutions. In this technique we use allyl alcohol (AA) to trap the reactive halogens $\left(\mathrm{Cl}^{*}(\mathrm{aq})\right.$ and $\left.\mathrm{Br}^{*}(\mathrm{aq})\right)$ and form stable, halogenated diols (3-chloropropanediol (3CPD) and 3-bromopropanediol (3BPD)) that are quantified.

Correspondence to: C. Anastasio

(canastasio@ucdavis.edu)
In chloride solutions the formation of $\mathrm{Cl}^{*}(\mathrm{aq})$ by ${ }^{\bullet} \mathrm{OH}$ occurs through reactions that are analogous to those in bromide solutions (see Part 1):

$\mathrm{Cl}^{-}+{ }^{\bullet} \mathrm{OH} \rightarrow{ }^{\bullet} \mathrm{ClOH}^{-}$

$\cdot \mathrm{ClOH}^{-}+\mathrm{Cl}^{-} \rightarrow{ }^{\bullet} \mathrm{Cl}_{2}^{-}+\mathrm{OH}^{-}$

$\cdot \mathrm{ClOH}^{-}+\mathrm{H}^{+} \rightarrow \mathrm{Cl}^{\bullet}+\mathrm{H}_{2} \mathrm{O}$

While $\mathrm{Cl}^{\bullet},{ }^{\bullet} \mathrm{Cl}_{2}^{-}$, and a number of other $\mathrm{Cl}^{*}$ species can form $3 \mathrm{CPD}$ in chloride solutions, under our conditions ${ }^{\bullet} \mathrm{Cl}_{2}^{-}$is the dominant source. In solutions containing both chloride and bromide, ${ }^{\bullet} \mathrm{Cl}_{2}^{-}$is a less important source of 3CPD and the mixed halogen species ${ }^{\circ} \mathrm{BrCl}^{-}$becomes the dominant source. ${ }^{\bullet} \mathrm{BrCl}^{-}$, and the molecular mixed halogen $\mathrm{BrCl}$, are also significant sources of $3 \mathrm{BPD}$ in mixed halide solutions. These species are formed from a number of reactions, including interactions such as

${ }^{\bullet} \mathrm{Cl}_{2}^{-}+\mathrm{Br}^{-} \rightarrow{ }^{\bullet} \mathrm{BrCl}^{-}+\mathrm{Cl}^{-}$

$\mathrm{Cl}^{-}+\mathrm{HOBr}+\mathrm{H}^{+} \rightarrow \mathrm{BrCl}+\mathrm{H}_{2} \mathrm{O}$

(Note that these reactions are from the supplementary material (Sects. S.1-S.12, Reactions 1-192, Eqs. S1-S41, and Tables S1-S6) that was introduced in Part 1. To avoid duplication, and because this paper refers to many of the equations from Part 1, we have also made the equation numbering continuous between Part 1 (Eqs. 1-10) and this paper (Eqs. 1119).)

In Part 1 we described the overall chemical probe technique, its use with competition kinetics, and its application to solutions containing bromide. In this paper we apply the technique to chloride solutions and to "mixed halide" solutions, i.e., those containing both bromide and chloride. As in Part 1, our first step here is to perform a series of experiments under different conditions in order to build and test a kinetic model of reactive halogen chemistry. The second step

Published by Copernicus GmbH on behalf of the European Geosciences Union. 
is to use this kinetic model to evaluate the overall chemical probe technique, and a series of three data treatments, under a range of experimental conditions.

\section{Experimental}

The key general aspects to the chemical probe technique are discussed in detail in Part 1. In the following sections, we give a brief overview of the technique and a more detailed description of the models and procedures that are specific to using the method in solutions containing either $\mathrm{Cl}^{-}$or both $\mathrm{Cl}^{-}$and $\mathrm{Br}^{-}$.

\subsection{Overview of experimental parameters}

The reagents (including Milli-Q water) used in this work are the same as described in Part 1 with the exception of $\mathrm{NaCl}$. In many of our experiments with chloride solutions the results can be affected by trace levels of $\mathrm{Br}^{-}$. Because we could find no source of $\mathrm{NaCl}$ that was bromide-free, we developed a technique to remove the small amounts of bromide present in chloride solutions (Sect. S.7). Using this technique with high purity $\mathrm{NaCl}$ (Sigma Aldrich; 99.999\%) we reduced $\mathrm{Br}^{-}$ levels from $\sim 0.007 \% \mathrm{~mol} \mathrm{Br} / \mathrm{mol} \mathrm{Cl}$ (in untreated chloride) to $<0.0002 \% \mathrm{~mol} \mathrm{Br} / \mathrm{mol} \mathrm{Cl}$, a level that did not significantly affect our experimental results.

During experiments aqueous samples $(\sim 23 \mathrm{~mL})$ containing halide, allyl alcohol (AA), and 1.0 mM hydrogen peroxide (as a photochemical source of $\bullet \mathrm{OH}$ ) were illuminated (313 nm light) in airtight, stirred, $5 \mathrm{~cm}$ quartz cells maintained at $20^{\circ} \mathrm{C}$. Aliquots of sample were removed at specified times and analyzed for 3XPD (i.e., 3-chloro-1,2-propanediol (3CPD), and/or 3-bromo-1,2-propanediol (3BPD)) and AA using techniques discussed in Part 1 . When required, sample $\mathrm{pH}$ was adjusted using $1.0 \mathrm{M} \mathrm{H}_{2} \mathrm{SO}_{4}$ or a mixture of $1.0 \mathrm{mM}$ sodium tetraborate and $0.30 \mathrm{M} \mathrm{NaOH}$. For each experiment the actinic flux was measured using 2-nitrobenzaldehyde actinometry (Anastasio et al., 1994). Dark controls were treated the same as illuminated samples except that they were prepared in $1 \mathrm{~cm}$ quartz cells, placed in a dark cell chamber $\left(20^{\circ} \mathrm{C}\right.$, stirred), and sampled at the final illumination time point. There was no loss of AA, and no formation of 3BPD or $3 \mathrm{CPD}$, in illuminated samples that did not contain $\mathrm{H}_{2} \mathrm{O}_{2}$, regardless of whether bromide and/or chloride were present. In addition, illumination of solutions containing $1.0 \mathrm{mM} \mathrm{H}_{2} \mathrm{O}_{2}$, $0.80 \mathrm{mM} \mathrm{Br}^{-}, 3 \mathrm{BPD}$ and/or 3CPD lead to no loss of 3XPD over the time scales of our experiments.

\subsection{Kinetic models}

Halide chemistry in the illuminated solutions was modeled with Acuchem (Braun et al., 1988). In Part 1, we developed a kinetic model ( $\mathrm{Br}^{-}$Full Model) that describes aqueous bromide chemistry. Here we extend this model to include chloride and mixed halide (i.e., bromide and chloride) reactions.
The model written for the chloride system $\left(\mathrm{Cl}^{-}\right.$Full Model $)$ consists of the reactions from Table S1, the reactions of ${ }^{\bullet} \mathrm{OH}$ and ${ }^{\bullet} \mathrm{CO}_{3}^{-}$with allyl alcohol (Table S3), aqueous chloride reactions (Table $\mathrm{S} 4$ ), and interactions of reactive chloride species $\left(\mathrm{Cl}^{*}(\mathrm{aq})\right)$ with AA (Table S5). The chemistry occurring in the mixed halide solutions is described in the "Mix Full Model". This model consists of the " $\mathrm{Br}^{-}$Full Model" (Tables S1-S3), aqueous chloride reactions (Table S4), reactions of $\mathrm{AA}$ with $\mathrm{Cl}^{*}(\mathrm{aq})$ and with mixed halogen species $\left(\mathrm{BrCl}^{*}(\mathrm{aq})={ }^{\bullet} \mathrm{BrCl}^{-}\right.$and $\left.\mathrm{BrCl}\right)$ (Table S5), and mixed halide reactions (Table S6).

Obtaining quantitative information (i.e., rates of formation $\left(R_{F}^{i}\right)$, steady-state concentrations $([i])$, and lifetimes $\left(\tau_{i}\right)$ ) for reactive halogen species $i$ requires knowing the yields of 3BPD and 3CPD formed from the reactions of $i$ with AA $\left(Y_{i}^{3 \mathrm{XPD}}\right)$. These yields were calculated as described in Sect. 2.2.3 of Part 1, and are based on the modeled rate constants for the reactions of species $i$ with AA (Tables S3 and S5). In our chloride experiments, dichloride radical anion $\left({ }^{\bullet} \mathrm{Cl}_{2}^{-}\right)$is responsible for most of 3CPD formation, while $\mathrm{Cl}^{\bullet}$ contributes only very little (typically $<4 \%$ ). Based on the modeled rate constants, yields of 3CPD from the reactions of ${ }^{\bullet} \mathrm{Cl}_{2}^{-}$and $\mathrm{Cl}^{\bullet}$ with AA are 0.095 and $\sim 0.2$, respectively.

In mixed halide solutions 3CPD can also be formed from the reaction of $\mathrm{AA}$ with ${ }^{-} \mathrm{BrCl}^{-}$or $\mathrm{BrCl}$, with yields of 0.0031 and $\sim 5 \times 10^{-5}$, respectively (Table S5). In addition to $\mathrm{Br}^{\circ}, \mathrm{Br}_{2}$, and $\mathrm{HOBr}$ (Part 1), 3BPD can also be formed by both $\mathrm{BrCl}$ and ${ }^{\circ} \mathrm{BrCl}^{-}$in mixed halide solutions. Based on modeled rate constants, the yield of 3BPD from the reaction of $\mathrm{BrCl}$ with $\mathrm{AA}$ is 0.50 (Table $\mathrm{S} 5$ ). The yield from - $\mathrm{BrCl}^{-}$is $\mathrm{pH}$ dependent: 0.078 at $\mathrm{pH} \leq 5.5,0$ at $\mathrm{pH} \geq 6.5$, and varying linearly between these values. We could find no rate constants for the reactions of $\mathrm{Cl}_{2}$ or $\mathrm{BrCl}$ with $\mathrm{AA}$ (Reactions 147-149, Table S5) or other alkenes in water. Fitting the kinetic model to the experimental data produced a total rate constant of $\mathrm{BrCl}$ with allyl alcohol of $1.0 \times 10^{8} \mathrm{M}^{-1} \mathrm{~s}^{-1}$ (Reactions 147-149) and a 3BPD yield of 0.50. Based on this we estimate that the total rate constant for the reaction of $\mathrm{Cl}_{2}$ with $\mathrm{AA}$ is $1.1 \times 10^{8} \mathrm{M}^{-1} \mathrm{~s}^{-1}$ (Reactions 138 and 139 , Table S5), but this value is not well constrained by our results.

While we were able to use published values to determine or constrain rate constants for the reaction of AA with a number of reactive halogen species (especially for $\mathrm{Br}^{*}(\mathrm{aq})$; Table S3), in many cases no literature values were available. In these cases we estimated rate constants based on fitting our model to our experimental results (e.g., see footnotes in Tables S3, S5, and S6). Similarly, for many of the mixed halide reactions (Table S6) there were no published rate constants available and we therefore compiled our set of reactions and rate constants by fitting model output to the measured rates of 3BPD and 3CPD formation and AA loss. As described in section 3.7, this dearth of independently determined reactions and rate constants is a weakness of our model, although we have confidence in the overall model because of its ability 
to describe our measured results over a wide range of experimental conditions.

\subsection{Competition kinetics}

There are two aspects that complicate our allyl alcohol chemical probe technique compared to past techniques: i) the addition of the probe compound (AA) causes a decrease in the rate of $\mathrm{X}^{*}(\mathrm{aq})$ formation because the AA scavenges ${ }^{\bullet} \mathrm{OH}$, and ii) the compounds formed from the reaction of $X^{*}(\mathrm{aq})$ with allyl alcohol are not specific to an individual species (i.e., 3BPD and 3CPD are each formed by several different species). These complications require that the raw data be corrected to compensate for these effects. In Part 1, the effects associated with i) and ii) were referred to as the "AA effect" and the " $F_{i}^{3 \mathrm{BPD}}$ effect", respectively. Here we refer to the latter effect as the " $F_{i}^{3 X P D}$ effect", where $F_{i}^{3 X P D}$ is the fraction of total 3BPD or 3CPD that is formed from the reaction of species $i$ with AA.

The dynamics of the reactive halogen species are determined from competition kinetics experiments where product formation rates (3BPD and 3CPD) are measured as a function of allyl alcohol concentration. From these experiments we calculate steady-state concentrations and other parameters for $\mathrm{X}^{*}(\mathrm{aq})$ using data from "inverse plots", i.e., plots of the inverse of the rate of $3 \mathrm{XPD}$ formation $\left(1 / R_{F}^{3 \mathrm{XPD}}\right)$ versus 1/[AA]. Recall from Part 1 that there are two general approaches to calculate $[i], R_{F}^{i}$, and $\tau_{i}$ from the inverse plots. The first approach (data treatment A) is only applicable for $\mathrm{Br}^{\bullet}$ in solutions containing only bromide (see Sect. 3.6.1 of Part 1) and cannot be used here. This is because this approach was derived as an analytical solution to a kinetic scheme involving ${ }^{\bullet} \mathrm{OH}, \mathrm{Br}^{-}$, and $\mathrm{Br}^{\bullet}$. Similar analytical expressions can be determined for other reactive halogens, but they cannot be solved because they contain concentrations of intermediate species that cannot currently be determined.

In the second, more general, approach we assume that AA has only a minor effect upon ${ }^{\bullet} \mathrm{OH}$ (and, therefore, upon $X^{*}(\mathrm{aq})$ formation) in the linear portion of the inverse plot (where [AA] is small and the "AA effect" is minimized). By making this assumption, the kinetic derivations are simplified and can be applied to the other $\mathrm{X}^{*}(\mathrm{aq})$ species. In this case, Eq. (S13) can be rewritten for all $\mathrm{X}^{*}$ (aq) species as:

$$
\frac{1}{R_{F, \text { tot }}^{3 \mathrm{XPD}}}=a^{\prime}+\frac{b^{\prime}}{[\mathrm{AA}]}
$$

where $R_{F, \text { tot }}^{3 X P D}$ is the total rate of formation of 3BPD or 3CPD and $a^{\prime}$ and $b^{\prime}$ are, respectively, the y-intercept and slope of the linear portion of the inverse plot. Using a procedure analogous to that described for $\mathrm{Br}^{*}(\mathrm{aq})$ in Part 1, we can derive general expressions for $a^{\prime}$ and $b^{\prime}$ :

$a^{\prime}=\frac{F_{i}^{3 \mathrm{XPD}}}{Y_{i}^{3 \mathrm{XPD}} R_{F}^{i}}$
$b^{\prime}=\frac{F_{i}^{3 \mathrm{XPD}}}{Y_{i}^{3 \mathrm{XPD}} k_{i}^{\mathrm{AA}}[i]}$

where $Y_{i}^{3 \mathrm{XPD}}$ is the yield of 3XPD from the reaction of species $i$ with AA (Sect. 2.2), $R_{F}^{i}$ and [i] are the rate of formation and concentration of species $i$, respectively, and $F_{i}^{3 X P D}$ is the fraction of 3XPD formed from species $i$ (Sect. S.12). (Note that these equations are the more general analogs of Eqs. S25-S27 derived in Part 1.) In the mixed halide system we calculate $F_{i}^{3 \mathrm{CPD}}$ based on ${ }^{\bullet} \mathrm{Cl}_{2}^{-}, \mathrm{Cl}^{\bullet}, \mathrm{Cl}_{2}$, $\mathrm{HOCl}, \mathrm{BrCl}$, and ${ }^{\bullet} \mathrm{BrCl}^{-}$, while for $F_{i}^{3 \mathrm{BPD}}$ we include $\mathrm{Br}^{\bullet}$, $\bullet \mathrm{Br}_{2}^{-}, \mathrm{Br}_{2}, \mathrm{HOBr}, \mathrm{BrCl}$, and ${ }^{-} \mathrm{BrCl}^{-}$. Other species (e.g., $\mathrm{Br}_{3}^{-}$and $\mathrm{Cl}_{3}^{-}$) are insignificant sources of 3BPD or 3CPD in our experiments but could be important under other conditions.

Equations (12) and (13) can be rearranged to solve for [i], $R_{F}^{i}$, and the lifetime of $i\left(\tau_{i}\right)$ :

$$
\begin{aligned}
& {[i]=\frac{F_{i}^{3 \mathrm{XPD}}}{b^{\prime} Y_{i}^{3 \mathrm{XPD}} k_{i}^{\mathrm{AA}}}} \\
& R_{F}^{i}=\frac{F_{i}^{3 \mathrm{XPD}}}{a^{\prime} Y_{i}^{3 \mathrm{XPD}}} \\
& \tau_{i}=\frac{a^{\prime}}{b^{\prime} k_{i}^{\mathrm{AA}}}=\frac{[i]}{R_{F}^{i}}
\end{aligned}
$$

As in the bromide system in Part 1 (Sect. 2.3), assuming that the AA effect is small in the linear region of the inverse plot can lead to errors in $[i], R_{F}^{i}$ and $\tau_{i}$ in the chloride and mixed halide systems, but we can generally correct for these biases using the kinetic model.

\section{Results and discussion}

\subsection{Overview of experimental approach}

Our first goal is to use our experimental results to construct a numerical model that describes the chemistry occurring in illuminated mixed halide solutions. We start by characterizing the rates of 3CPD formation $\left(R_{F, \text { tot }}^{3 C \mathrm{CD}}\right)$ and allyl alcohol loss $\left(R_{L}^{\mathrm{AA}}\right)$ in solutions containing only chloride (Sect. 3.2) to make a model of chloride chemistry $\left(\mathrm{Cl}^{-}\right.$Full Model). This model is then combined with the $\mathrm{Br}^{-}$Full Model (Part 1), and a series of mixed halide reactions, to make the "Mix Full Model", which describes the chemistry in mixed halide solutions. This final model is tested and constrained using several different sets of experiments under various solution conditions (Sect. 3.3) and is then used to evaluate the kinetic equations for $[i], R_{F}^{i}$, and $\tau_{i}$ using model-derived data (Sect. 3.5). Finally, we test the ability of the probe technique to experimentally determine reactive halogen kinetics in solutions containing both $\mathrm{Br}^{-}$and $\mathrm{Cl}^{-}$(Sect. 3.6). 
Table 1. Parameters for the competition kinetics experiments.

\begin{tabular}{|c|c|c|c|c|c|c|c|c|c|c|}
\hline \multirow{2}{*}{$\begin{array}{c}\text { Exp } \\
\#\end{array}$} & \multirow[b]{2}{*}{$\mathrm{pH}$} & \multicolumn{2}{|c|}{ [AA] Range Tested } & \multicolumn{4}{|c|}{ Linear $[\mathrm{AA}]$ Range $^{\mathrm{a}}(\mu \mathrm{M})$} & \multicolumn{3}{|c|}{$\begin{array}{c}\text { Agreement Between Model } \\
\text { and Experiment }{ }^{\mathrm{c}} \text { (Average RPD) }\end{array}$} \\
\hline & & $(\mu \mathrm{M})$ & $\mathrm{n}^{\mathrm{b}}$ & 3BPD & $n^{b}$ & 3CPD & $\mathrm{n}^{\mathrm{b}}$ & 3BPD & 3CPD & AA \\
\hline \multicolumn{11}{|c|}{ Chloride Experiment $\left(\left[\mathrm{Cl}^{-}\right]=0.56 \mathrm{M}\right.$, no $\left.\mathrm{Br}^{-}\right)$} \\
\hline 1 & 5.4 & $2-75$ & 8 & - & - & $2-15$ & 4 & - & 7.5 & 22 \\
\hline \multicolumn{11}{|c|}{ Mixed Halide Experiments $\left(\left[\mathrm{Cl}^{-}\right]=0.56 \mathrm{M},\left[\mathrm{Br}^{-}\right]=0.80 \mathrm{mM}\right)$} \\
\hline 2 & 3.0 & $2-150$ & 11 & $2-25$ & 7 & $20-150$ & 6 & 10 & 15 & 19 \\
\hline 3 & 5.5 & $10-3000$ & 12 & $10-250$ & 8 & $10-500$ & 9 & 25 & 18 & 13 \\
\hline 4 & 8.0 & $20-150$ & 6 & $20-150$ & 6 & $20-150$ & 6 & 49 & 45 & 22 \\
\hline
\end{tabular}

The concentration of $\mathrm{H}_{2} \mathrm{O}_{2}$ for all experiments was $0.98-1.0 \mathrm{mM}$. The photolysis rate constant for $\mathrm{H}_{2} \mathrm{O}_{2}\left(j_{\mathrm{H} 2 \mathrm{O} 2}\right)$ was $3.3 \times 10^{-6} \mathrm{~s}^{-1}$ for all experiments.

a Range of allyl alcohol concentration where the inverse plot based on the total rate of 3XPD formation is linear. Note that the linear range can change when the inverse plots are based on individual species, as is done in treatment $\mathrm{C}$.

b Number of experimental data points sampled within the specified range.

c Agreement between the experimental data and model output, calculated as the average of the absolute values of the relative percent difference (RPD) between the model and experimental values of $R_{F \text {, tot }}^{3 \mathrm{PPD}}$ (and $R_{L}^{\mathrm{AA}}$ ) over the entire range of allyl alcohol concentrations. Note that the listed values for $R_{F \text {, tot }}^{3 \mathrm{XPD}}$ and $R_{L}^{\mathrm{AA}}$ also apply to $1 / R_{F}^{3 \mathrm{XPD}}$, tot $1 / R_{L}^{\mathrm{AA}}$, respectively.

\subsection{Chloride experiments}

$$
\begin{aligned}
& \text { 3.2.1 Rates of formation of } 3 \mathrm{CPD}\left(R_{F, \text { tot }}^{3 \mathrm{CPD}}\right) \text { and loss of } \mathrm{AA} \\
& \left(R_{L}^{\mathrm{AA}}\right) \text { as a function of } \mathrm{pH}
\end{aligned}
$$

All solutions contained $1.0 \mathrm{mM} \mathrm{H}_{2} \mathrm{O}_{2}, 75 \mu \mathrm{M} \mathrm{AA}$, and seawater concentrations of chloride $(0.56 \mathrm{M} \mathrm{NaCl}$, from $\mathrm{NaCl}$ that was treated to remove $\mathrm{Br}^{-}$; Sect. S.7). As shown in Fig. 1a, the experimental values of $R_{F, \text { tot }}^{3 C P D}$ exhibit a strong dependence on $\mathrm{pH}$, rising quickly at $\mathrm{pH}<5.5$ as a result of the acid-dependent formation of $\mathrm{Cl}^{\bullet}$ (Reaction 97). Measured values of $R_{L}^{\mathrm{AA}}$ (Fig. 1b) show a much weaker dependence on $\mathrm{pH}$, increasing only slightly with decreasing $\mathrm{pH}$. Also shown in Figs. 1a and $1 \mathrm{~b}$ are results from the $\mathrm{Cl}^{-}$Full Model, which closely predicts both $R_{F, \text { tot }}^{3 \mathrm{CPD}}$ and $R_{L}^{\mathrm{AA}}$ as a function of $\mathrm{pH}$. Based on model results the dichloride radical anion $\left({ }^{\bullet} \mathrm{Cl}_{2}^{-}\right)$is responsible for $\geq 99 \%$ of the $3 \mathrm{CPD}$ formed at all $\mathrm{pH}$ values in these experiments, while other chlorinating species $\left(\mathrm{Cl}_{2}\right.$, $\mathrm{HOCl}$, and $\mathrm{Cl}^{\bullet}$ ) are insignificant.

$$
\begin{aligned}
& \text { 3.2.2 Rates of formation of 3CPD }\left(R_{F, \text { tot }}^{3 \mathrm{CPD}}\right) \text { and loss of AA } \\
& \left(R_{L}^{\mathrm{AA}}\right) \text { as a function of [AA] }
\end{aligned}
$$

Experiments were conducted as outlined in Sect. 3.2.1 except in this case the $\mathrm{pH}$ was held constant at 5.4 and [AA] was varied from 2-75 $\mu \mathrm{M}$ (Table 1). As shown in Figs. 2a and $\mathrm{b}$, the $\mathrm{Cl}^{-}$Full Model does a good job of predicting both $R_{F, \text { tot }}^{3 \mathrm{CPD}}$ and $R_{L}^{\mathrm{AA}}$, with average relative percent differences (RPD) between the model and experimental values of 7.5 and $22 \%$ for $R_{F, \text { tot }}^{3 \mathrm{CPD}}$ and $R_{L}^{\mathrm{AA}}$, respectively (Table 1 ). As expected, $R_{F, \text { tot }}^{3 \mathrm{CPD}}$ decreases at higher [AA] where allyl alco- hol becomes the dominant sink for ${ }^{\bullet} \mathrm{OH}$, thereby decreasing chloride oxidation and $\mathrm{Cl}^{*}(\mathrm{aq})$ formation (Fig. 2a). It is interesting to note that the decrease in 3CPD formation in the chloride solution occurs at much lower [AA] than does the decrease in 3BPD formation in the bromide system $(\sim 15 \mu \mathrm{M}$ versus $\sim 300 \mu \mathrm{M})$. This is because $\mathrm{Cl}^{-}$is less efficient at scavenging ${ }^{\bullet} \mathrm{OH}$ than is $\mathrm{Br}^{-}$at $\mathrm{pH} 5.5$ and so less $\mathrm{AA}$ is required to outcompete $\mathrm{Cl}^{-}$. Based on model results, ${ }^{\bullet} \mathrm{Cl}_{2}^{-}$ is responsible for $95-100 \%$ of the 3CPD formed between 2 and $75 \mu \mathrm{M} \mathrm{AA}$, while $\mathrm{Cl}^{\bullet}$ is responsible for $\leq 5 \%$.

\subsubsection{Measurements of gaseous reactive chlorine $(\mathrm{Cl} *(\mathrm{~g}))$}

As was the case for the bromide system, we also conducted an experiment to measure the production and release of $\mathrm{Cl}^{*}(\mathrm{~g})$ (i.e., $\mathrm{Cl}_{2}$ and $\mathrm{HOCl}$ ) from an air-purged, illuminated solution (pH 3.9) containing $3.5 \mathrm{M} \mathrm{NaCl}$ and $0.10 \mathrm{M} \mathrm{NaNO}_{3}$ (as a photochemical source of $\bullet \mathrm{OH}$ ), but no allyl alcohol. The experiment was conducted as described in Matthew et al. (2003) except that nitrate was used instead of $\mathrm{H}_{2} \mathrm{O}_{2}$ as a source of ${ }^{\bullet} \mathrm{OH}$ and gases were collected in a bubbler containing $10 \mathrm{~mL}$ of $0.50 \mathrm{M} \mathrm{Na}_{2} \mathrm{SO}_{3}$ and $34.0 \mathrm{mM} \mathrm{Na}_{2} \mathrm{CO}_{3}$ instead of a carbonate-coated denuder. The low apparent rate of $\mathrm{Cl}^{*}(\mathrm{~g})$ collection in the experiment $\left(8.8 \mathrm{nmol} \mathrm{h}^{-1}\right)$ is less than the equivalent average rate from a series of blanks $\left(16 \pm 22 \mathrm{nmol} \mathrm{h}^{-1}\right)$. While the blank value is high, it appears that no significant amounts of $\mathrm{Cl}^{*}(\mathrm{~g})$ were produced in the bubbling experiment, which is consistent with our model results $\left(<4 \times 10^{-4} \mathrm{nmol} \mathrm{Cl}^{*}(\mathrm{~g}) \mathrm{h}^{-1}\right.$ at any $\mathrm{pH}$ value between 3 and 8). 


\subsection{Mixed halide experiments}

The experiments in the following sections were designed to constrain our mixed halide model (i.e., the Mix Full Model). This model consists of the validated $\mathrm{Br}^{-}$and $\mathrm{Cl}^{-}$Full Models along with a number of mixed halide reactions (154-192, Table S6). One important effect of these reactions is to convert radical chloride species $\left({ }^{\bullet} \mathrm{ClOH}^{-},{ }^{\bullet} \mathrm{Cl}_{2}^{-}\right.$and $\left.\mathrm{Cl}^{\bullet}\right)$ into $\cdot \mathrm{BrCl}^{-}$(e.g., Reactions 171-173). The existence of ${ }^{\bullet} \mathrm{BrCl}^{-}$ has only been quantified recently (Donati, 2002; Ershov, 2004) and our experimental evidence indicates that it is an important species in mixed halide systems in the presence of •OH (Matthew, 2002).

3.3.1 Measurements of $R_{F, \text { tot }}^{3 \mathrm{BPD}}, R_{F, \text { tot }}^{3 \mathrm{CPD}}$ and $R_{L}^{\mathrm{AA}}$ as a function of $\left[\mathrm{Br}^{-}\right]$

Experiments were conducted at $\mathrm{pH} 5.4$ with solutions containing $0.56 \mathrm{M} \mathrm{NaCl}$ (from purified $\mathrm{NaCl}$; Sect. S.7), $1.0 \mathrm{mM}$ $\mathrm{H}_{2} \mathrm{O}_{2}, 75 \mu \mathrm{M}$ AA, and $0-800 \mu \mathrm{M} \mathrm{NaBr}$. As shown in Fig. 3a, $R_{F \text {.tot }}^{3 \mathrm{BPD}}$ rises quickly between 0 and $\sim 150 \mu \mathrm{M} \mathrm{Br}^{-}$ but rises only gradually at higher bromide concentrations. In contrast, $R_{F, \text { tot }}^{3 \mathrm{CPD}}$ decreases with increasing $\left[\mathrm{Br}^{-}\right]$. Values for $R_{L}^{\mathrm{AA}}$ (Fig. 3b) decrease with increasing $\left[\mathrm{Br}^{-}\right]$because the bromide scavenges ${ }^{\bullet} \mathrm{OH}$, resulting in decreased destruction of AA by ${ }^{\bullet} \mathrm{OH}$. Model results for $R_{F \text {,tot }}^{3 \mathrm{BPD}}$ and $R_{F, \text { tot }}^{3 \mathrm{CPD}}$ show that the Mix Full Model generally does a good job of predicting these two quantities, although it underpredicts 3CPD at low bromide concentrations (Fig. 3a). In addition, the model does a good job of predicting $R_{L}^{\mathrm{AA}}$ at $\left[\mathrm{Br}^{-}\right] \geq 300 \mu \mathrm{M}$, but underestimates AA loss at lower $\left[\mathrm{Br}^{-}\right]$(Fig. 3b).

Based on model results, in these experiments ${ }^{\circ} \mathrm{BrCl}^{-}$ and $\mathrm{Br}^{\bullet}$ are responsible for $\sim 74 \%$ and $\sim 23 \%$ of the 3BPD formed, respectively, at all bromide concentrations. ${ }^{\bullet} \mathrm{Cl}_{2}^{-}$ and ${ }^{\bullet} \mathrm{BrCl}^{-}$are primarily responsible for 3CPD formation and their contributions vary significantly with $\left[\mathrm{Br}^{-}\right]$. For example, at $10 \mu \mathrm{M} \mathrm{Br}^{-},{ }^{\bullet} \mathrm{Cl}_{2}^{-}$and ${ }^{\bullet} \mathrm{BrCl}^{-}$are responsible for $88 \%$ and $12 \%$, respectively, of 3CPD, while at $800 \mu \mathrm{M} \mathrm{Br}^{-}$ approximately $95 \%$ of $3 \mathrm{CPD}$ is from ${ }^{\bullet} \mathrm{BrCl}^{-}$.

3.3.2 Measurements of $R_{F \text {,tot }}^{3 \mathrm{BPD}}, R_{F \text {,tot }}^{3 \mathrm{CPD}}$ and $R_{L}^{\mathrm{AA}}$ as a function of $\mathrm{pH}$

Experiments were conducted on solutions containing $0.80 \mathrm{mM} \mathrm{NaBr}, 0.56 \mathrm{M} \mathrm{NaCl}$ (untreated), $1.0 \mathrm{mM} \mathrm{H}_{2} \mathrm{O}_{2}$, and $75 \mu \mathrm{M}$ AA. As shown in Fig. 4a, the model does a good job of explaining the $R_{F, \text { tot }}^{3 \mathrm{BPD}}$ measurements. The drop in $R_{F, \text { tot }}^{3 \mathrm{BPD}}$ between $\mathrm{pH} 5.5$ and 6.5 is due to the decrease in the yield of 3BPD from the reaction of ${ }^{\bullet} \mathrm{BrCl}^{-}$with $\mathrm{AA}\left(Y_{\mathrm{BrCl}^{-}}^{3 \mathrm{BPD}}\right)$ (Sect. 2.2). While the model somewhat overpredicts $R_{F \text {,tot }}^{3 \mathrm{CPD}}$ and $R_{L}^{\mathrm{AA}}$, model values are always within the measurement error limits (Figs. 4b-c).

Under these experimental conditions 3BPD is formed primarily from ${ }^{\bullet} \mathrm{BrCl}^{-}, \mathrm{Br}^{\bullet}$ and $\mathrm{BrCl}$, with their relative con-
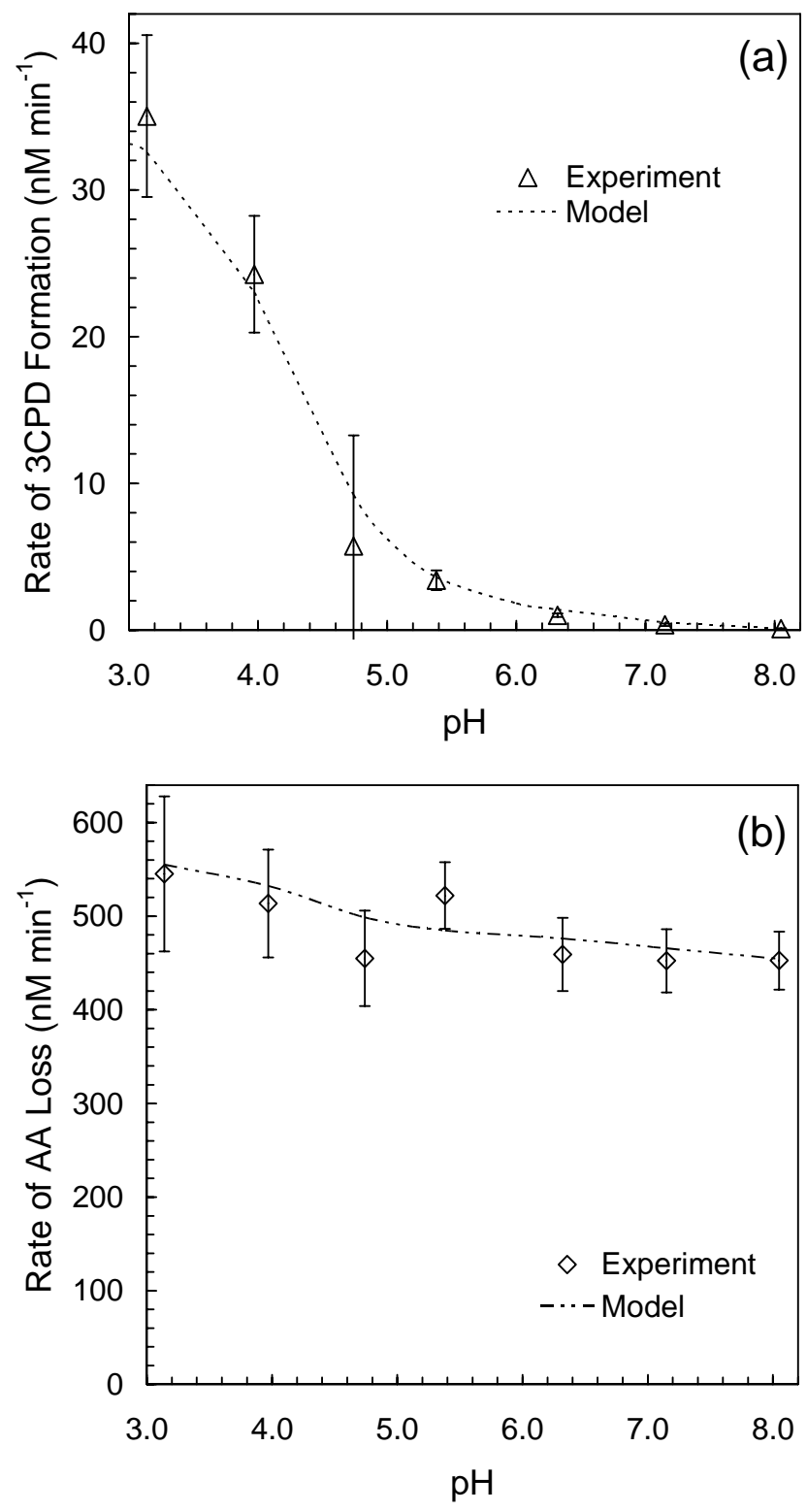

Fig. 1. (a) Rate of 3-chloro-1,2-propanediol (3CPD) formation $\left(R_{F, \text { tot }}^{3 \mathrm{CPD}}\right)$ as a function of $\mathrm{pH}$ in illuminated $(313 \mathrm{~nm})$ aqueous chloride solutions $\left(\left[\mathrm{Cl}^{-}\right]=0.56 \mathrm{M}\right)$ containing $1.0 \mathrm{mM} \mathrm{H}_{2} \mathrm{O}_{2}$ and $75 \mu \mathrm{M}$ AA. The triangles are experimental values of $R_{F}^{3 \mathrm{CPD}}$, tot with error bars representing $90 \%$ confidence intervals (CI). CI were calculated from the standard errors of the slopes from plots of 3CPD concentration versus illumination time at each $\mathrm{pH}$. The dashed lines are model results from the $\mathrm{Cl}^{-}$Full Model. (b) Rate of allyl alcohol loss $\left(R_{L}^{\mathrm{AA}}\right)$ under conditions described in Fig. 1a. The diamonds are experimental values of $R_{L}^{\mathrm{AA}}$, with error bars representing $90 \%$ confidence intervals $(\mathrm{CI})$, calculated from the standard errors of the slopes from plots of AA concentration versus illumination time. The dot-dashed lines are model results from the $\mathrm{Cl}^{-}$Full Model.

tributions changing as a function of $\mathrm{pH}$. Unlike the case in bromide solutions, where $\mathrm{Br}_{2}$ is the dominant precursor for 

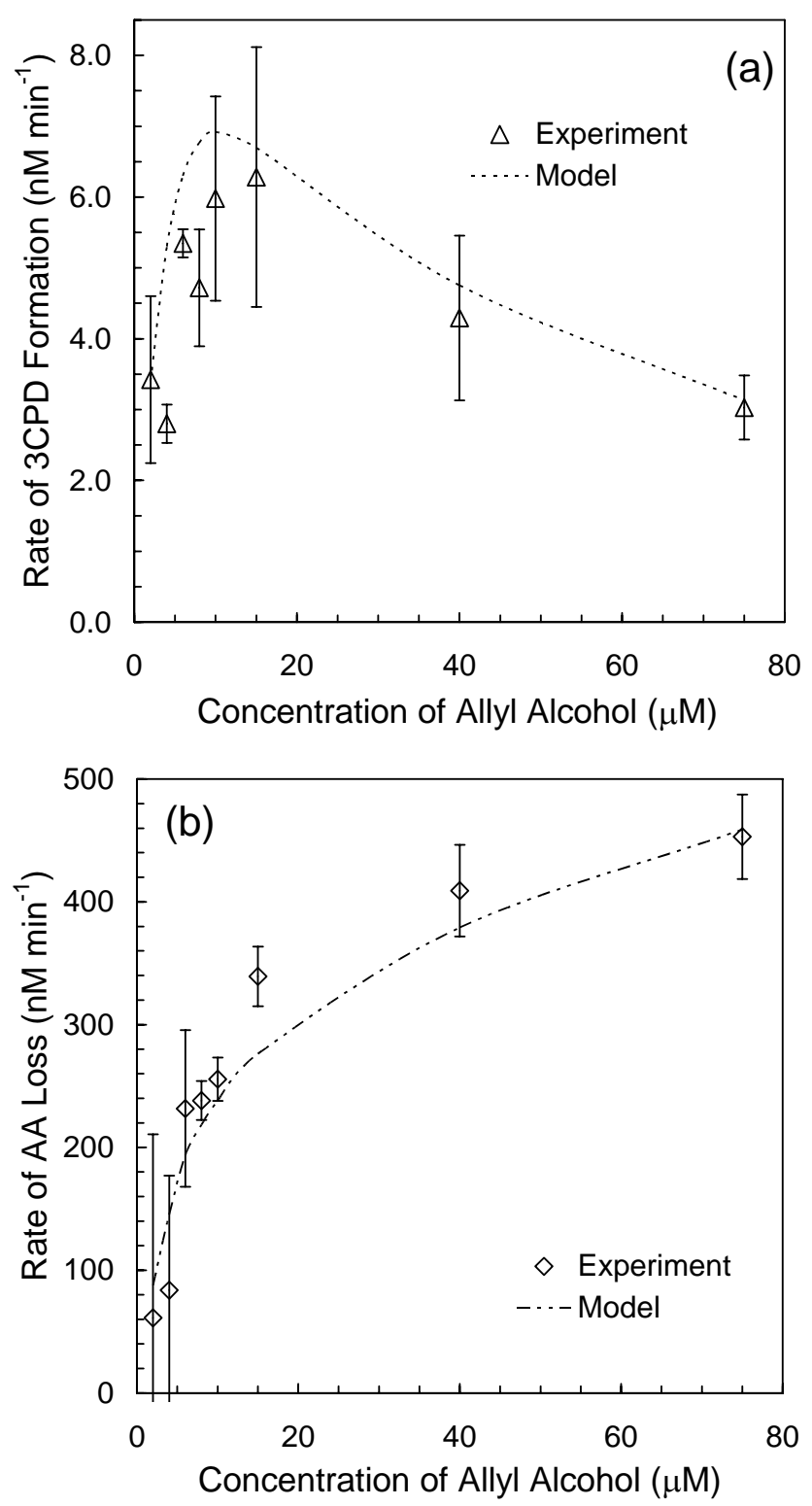

Fig. 2. (a) Rate of 3-chloro-1,2-propanediol (3CPD) formation $\left(R_{F, \text { tot }}^{3 \mathrm{CPD}}\right)$ as a function of $[\mathrm{AA}]$ in illuminated $(313 \mathrm{~nm})$ aqueous chloride solutions $\left(\left[\mathrm{Cl}^{-}\right]=0.56 \mathrm{M}, \mathrm{pH}=5.4\right)$ containing $1.0 \mathrm{mM}$ $\mathrm{H}_{2} \mathrm{O}_{2}$. Symbols, error bars, and lines are the same as described in Fig. 1a. (b) Rate of allyl alcohol loss $\left(R_{L}^{\mathrm{AA}}\right)$ as a function of [AA] in the illuminated solutions described in Fig. 2a. Symbols, error bars, and lines are the same as in Fig. 1b.

3BPD at $\mathrm{pH} 3.0$ (see Part 1), in the mixed halide solutions $\mathrm{BrCl}$ is the most important source of 3BPD at low $\mathrm{pH}$. For example, at $\mathrm{pH} 3.0, \mathrm{BrCl},{ }^{\bullet} \mathrm{BrCl}^{-}$, and $\mathrm{Br}^{\bullet}$ account for 61 , 23 and $11 \%$, respectively, of 3BPD. At pH 5.5, these contributions change to approximately 8,67 , and $18 \%$, respectively, while at $\mathrm{pH} \geq 6.5, \mathrm{Br}^{\bullet}$ accounts for $\geq 95 \%$ of the $3 \mathrm{BPD}$ formed. The primary species responsible for 3CPD formation is ${ }^{\bullet} \mathrm{BrCl}^{-}$although ${ }^{\bullet} \mathrm{Cl}_{2}^{-}$is also significant at low $\mathrm{pH}$.
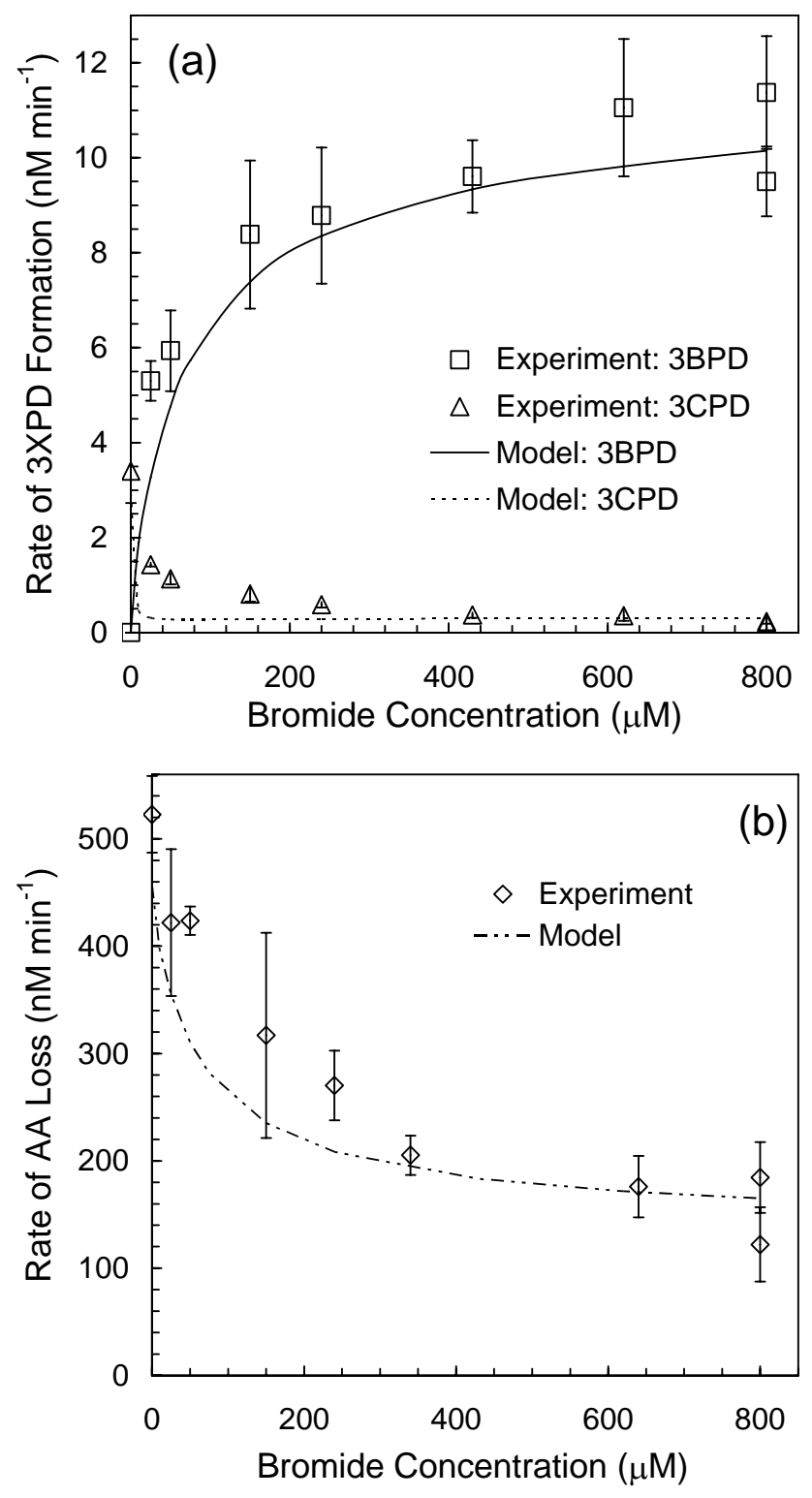

Fig. 3. (a) Rates of 3-bromo-1,2-propane-diol (3BPD) and 3chloro-1,2-propanediol (3CPD) formation $\left(R_{F \text {, tot }}^{3 \mathrm{BPD}}\right.$ and $R_{F \text {, tot }}^{3 \mathrm{CPD}}$, respectively) as a function of $\left[\mathrm{Br}^{-}\right]$in illuminated $(313 \mathrm{~nm})$ aqueous chloride solutions $\left(\left[\mathrm{Cl}^{-}\right]=0.56 \mathrm{M}, \mathrm{pH}=5.4\right)$ containing $1.0 \mathrm{mM}$ $\mathrm{H}_{2} \mathrm{O}_{2}$ and $75 \mu \mathrm{M}$ AA. The squares and triangles are the experimental values of $R_{F}^{3 \mathrm{BPD}}$, tot and $R_{F}^{3 \mathrm{CPD} \text {, tot }}$, respectively, while the solid and dashed lines are the Mix Full Model values for $R_{F \text {, tot }}^{3 B P D}$ and $R_{F \text {, tot }}^{3 C \text {, }}$, respectively. Error bars are the same as described in Fig. 1a. (b) Rate of allyl alcohol loss $\left(R_{L}^{\mathrm{AA}}\right)$ in the experiments described in Fig. 3a. The diamonds are the experimental values of $R_{L}^{\mathrm{AA}}$, while the dot-dashed lines are the Mix Full Model values. The error bars are the same as in Fig. 1b.

For example, at $\mathrm{pH} 3$ these species account for $\sim 83$ and $\sim 10 \%$ of $3 \mathrm{CPD}$, respectively, while at $\mathrm{pH} \geq 5.5^{\bullet} \mathrm{BrCl}^{-}$forms $\geq 94 \%$ of 3 CPD. Note that all of these values are for solutions 
with $75 \mu \mathrm{M}$ allyl alcohol and that the contributions depend on $[\mathrm{AA}]$.

3.3.3 Measurements of $R_{F, \text { tot }}^{3 \mathrm{BPD}}, R_{F, \text { tot }}^{3 \mathrm{CPD}}$ and $R_{L}^{\mathrm{AA}}$ as a function of $[\mathrm{AA}]$

Experiments were conducted as in Sect. 3.3.2, except that the concentration of allyl alcohol was varied in solutions of $\mathrm{pH}$ 3.0, 5.5, and 8.0 (Experiments 2-4 in Table 1). In addition to further testing the Mix Full Model, these experiments represent the competition kinetics experiments for the mixed halide system (Sect. 3.6). Experimental values for $R_{F, \text { tot }}^{3 \mathrm{BPD}}$ and $R_{F, \text { tot }}^{3 \mathrm{CPD}}$ at $\mathrm{pH} 3.0$ (Experiment 2, Table 1) are shown in Fig. 5a along with the corresponding model results. While measured rates of 3BPD formation are 30-600 times greater than rates of $3 \mathrm{CPD}$ formation at this $\mathrm{pH}$, the model does a good job of matching both of these rates: average absolute RPD values between the model and experiment are $10 \%$ and $15 \%$ for $R_{F, \text { tot }}^{3 \mathrm{BPD}}$ and $R_{F, \text { tot }}^{3 \mathrm{CPD}}$, respectively. The Mix Full Model also does a reasonable job of matching experimental values of $R_{L}^{\mathrm{AA}}$ (Fig. 5b), with an average RPD between the model and experimental values of $19 \%$.

As seen in Table 1, the Mix Full Model also does a good job of matching the experimental data at $\mathrm{pH}$ 5.5: the average RPDs between modeled and measured values for $R_{F, \text { tot }}^{3 \mathrm{BPD}}$, $R_{F, \text { tot }}^{3 \mathrm{CPD}}$ and $R_{L}^{\mathrm{AA}}$ are 25,18 , and $13 \%$, respectively. In the $\mathrm{pH} 8.0$ experiment, where the overall reactivity is lower, the agreement is not as good, with average ratios of (model value)/(experiment value) of $1.7,1.6$, and 1.0 for $R_{F, \text { tot }}^{3 \mathrm{BPD}}$, $R_{F, \text { tot }}^{3 \mathrm{CPD}}$ and $R_{L}^{\mathrm{AA}}$, respectively, and corresponding RPD values of 49,45 , and $22 \%$.

\subsubsection{Measurements of $\mathrm{Br}^{*}(\mathrm{~g})$}

In a separate set of experiments to test our understanding of mixed halide chemistry, we measured the formation and release of reactive gaseous bromide species $\left(\mathrm{Br}^{*}(\mathrm{~g})\right)$ in the absence of allyl alcohol, as done in previously reported (Matthew et al., 2003). In these experiments we illuminated $(313 \mathrm{~nm})$ air-purged solutions containing $0.80 \mathrm{mM}$ $\mathrm{Br}^{-}, 0.56 \mathrm{M} \mathrm{Cl}^{-}$, and $1.0 \mathrm{mM} \mathrm{H}_{2} \mathrm{O}_{2}$ and trapped the volatile $\mathrm{Br}^{*}(\mathrm{~g})$ on downstream denuders that were then analyzed by ion chromatography. By adding reactions for the evaporation of $\mathrm{Br}_{2}$ and other volatile species, the Mix Full Model (with $[\mathrm{AA}]=0 \mu \mathrm{M})$ accurately describes the release of $\mathrm{Br}^{*}(\mathrm{aq})$ from these solutions as a function of $\mathrm{pH}$. These experiments provide further evidence that this model correctly describes mixed halide chemistry in our experimental solutions. Furthermore, because these results were generated with experimental and analytical methods different from our chemical probe methods, they represent an independent check on the model.

Taken together, our Br* $(\mathrm{g})$ and 3XPD results demonstrate that the Mix Full Model adequately describes mixed halide chemistry over a wide range of experimental conditions,
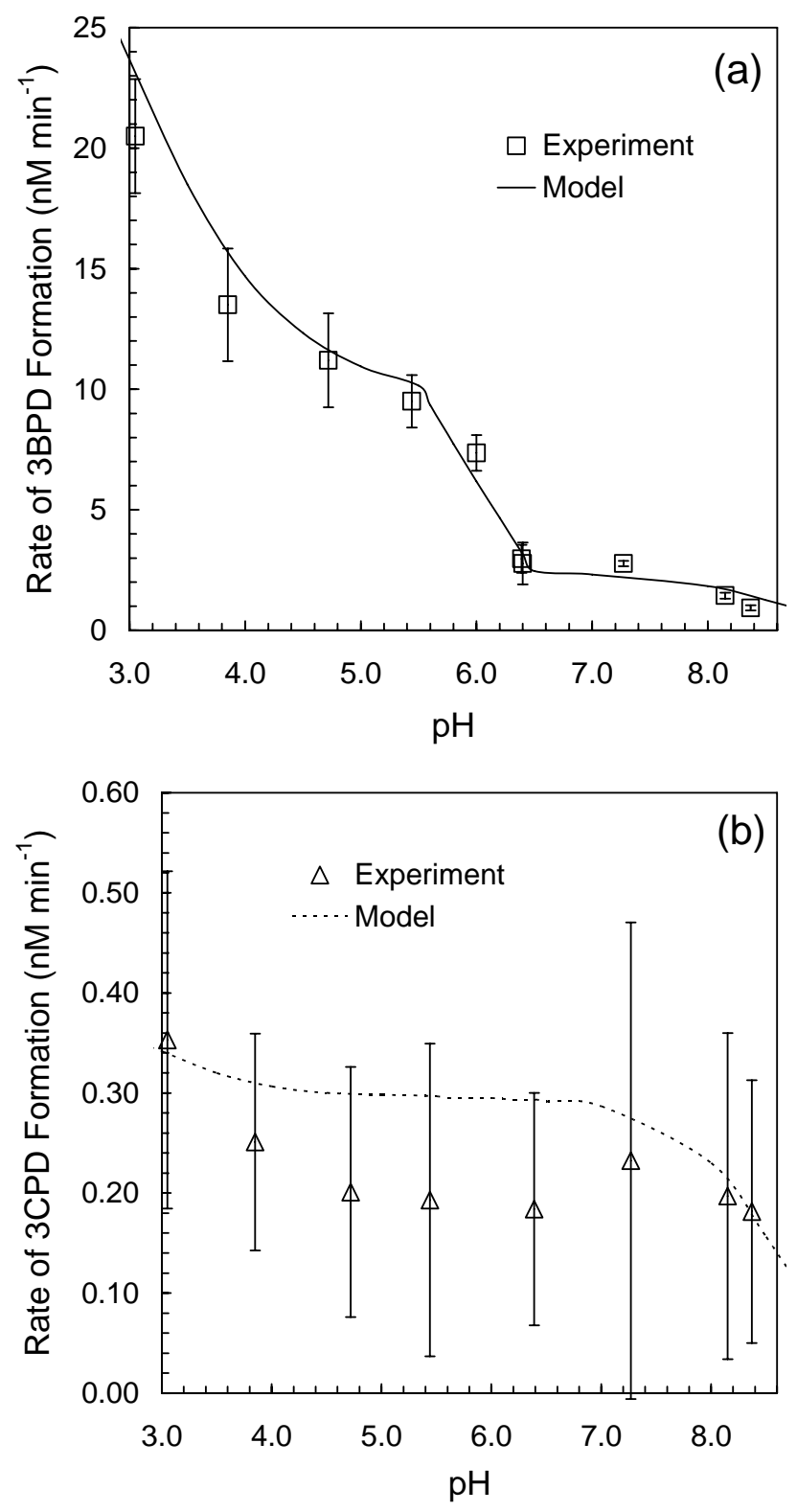

Fig. 4. (a) Rate of 3-bromo-1,2-propane-diol (3BPD) formation $\left(R_{F, \text { tot }}^{3 \mathrm{BPD}}\right)$ as a function of $\mathrm{pH}$ in illuminated $(313 \mathrm{~nm})$ aqueous mixed halide solutions $\left(\left[\mathrm{Cl}^{-}\right]=0.56 \mathrm{M},\left[\mathrm{Br}^{-}\right]=0.80 \mathrm{mM}\right)$ containing $1.0 \mathrm{mM} \mathrm{H}_{2} \mathrm{O}_{2}$ and $75 \mu \mathrm{M}$ AA. The symbols, lines, and error bars are the same as described in Fig. 3a. (b) Rate of 3-chloro1,2-propanediol (3CPD) formation $\left(R_{F, \text { tot }}^{3 \mathrm{CPD}}\right)$ in the experiments described in Fig. 4a. The symbols, lines, and error bars are the same as in Fig. 3a. (c) Rate of allyl alcohol loss $\left(R_{L}^{\mathrm{AA}}\right)$ in the experiments described in Fig. 4a. The symbols, lines, and error bars are the same as described in Fig. 3b.

which gives us confidence that the model can be used to evaluate the kinetic equations and performance of the chemical probe technique in mixed halide systems. 
Table 2. Results from the kinetic analyses of the model and experimental data from the competition kinetics experiments.

\begin{tabular}{|c|c|c|c|c|c|c|c|c|c|c|c|c|}
\hline \multirow[b]{3}{*}{ Species $(i)$} & \multirow{2}{*}{\multicolumn{2}{|c|}{ Expected Values $^{\mathrm{a}}$}} & \multirow[b]{3}{*}{ D.T. } & \multirow{3}{*}{$\begin{array}{l}\text { Fraction of 3XPD } \\
\text { from Listed } \\
\mathrm{X}^{*} \text { Species, } \\
F_{i}^{3 \mathrm{XPD}}(1 \mathrm{RSD})^{\mathrm{c}}\end{array}$} & \multicolumn{4}{|c|}{ Model Value with Data Treatment (MVDT) ${ }^{\mathrm{d}}$} & \multicolumn{4}{|c|}{ Experimental Value with Data Treatment (EVDT) ${ }^{\mathrm{e}}$} \\
\hline & & & & & \multicolumn{2}{|c|}{ Rate of formation, $R_{F}^{i}$} & \multicolumn{2}{|c|}{ Concentration, $[i]$} & \multicolumn{2}{|c|}{ Rate of formation, $R_{F}^{i}$} & \multicolumn{2}{|c|}{ Concentration, $[i]$} \\
\hline & $R_{F}^{i}\left(\mathrm{M} \mathrm{s}^{-1}\right)$ & {$[i](\mathrm{M})$} & & & Value $\left(\mathrm{M} \mathrm{s}^{-1}\right)$ & $\left\{\frac{\text { MVDT }}{\operatorname{Exp}}\right\}$ & Value (M) & $\left\{\frac{\text { MVDT }}{\operatorname{Exp}}\right\}$ & Value $\left(\mathrm{M} \mathrm{s}^{-1}\right)$ & $\left\{\frac{\text { EVDT }}{\operatorname{Exp}}\right\}$ & Value (M) & $\left.\frac{\text { EVDT }}{\operatorname{Exp}}\right\}$ \\
\hline \multicolumn{13}{|c|}{ Experiment $\# 1\left(\left[\mathrm{Cl}^{-}\right]=0.56 \mathrm{M}, \mathrm{pH}=5.4, \mathrm{no} \mathrm{Br}^{-}\right)$} \\
\hline $\mathrm{Cl}^{\bullet}$ & $2.7 \times 10^{-9}$ & $3.2 \times 10^{-16}$ & B & $0.03(0.37)$ & $2.3 \times 10^{-11}$ & $\{0.01\}$ & $1.4 \times 10^{-15}$ & $\{4.3\}$ & $(1.6 \pm 0.02) \times 10^{-11}$ & $\{0.01\}$ & $(1.8 \pm 0.03) \times 10^{-15}$ & $\{5.6\}$ \\
\hline \multirow[t]{2}{*}{$\cdot \mathrm{Cl}_{2}^{-}$} & $4.4 \times 10^{-9}$ & $1.1 \times 10^{-11}$ & B & $0.97(0.01)$ & $1.9 \times 10^{-9}$ & $\{0.42\}$ & $8.5 \times 10^{-12}$ & $\{0.80\}$ & $(1.3 \pm 0.02) \times 10^{-9}$ & $\{0.29\}$ & $(1.1 \pm 0.02) \times 10^{-11}$ & $\{1.1\}$ \\
\hline & & & $\mathrm{C}$ & 1 & $4.6 \times 10^{-9}$ & $\{1.1\}$ & $8.8 \times 10^{-12}$ & $\{0.84\}$ & $(2.9 \pm 0.03) \times 10^{-9}$ & $\{0.65\}$ & $(1.2 \pm 0.02) \times 10^{-11}$ & $\{1.2\}$ \\
\hline \multicolumn{13}{|c|}{ Experiment $\# 2\left(\left[\mathrm{Cl}^{-}\right]=0.56 \mathrm{M},\left[\mathrm{Br}^{-}\right]=0.80 \mathrm{mM}, \mathrm{pH}=3.0\right)$} \\
\hline \multirow[t]{2}{*}{$\mathrm{Br}^{\bullet}$} & $6.4 \times 10^{-9}$ & $1.6 \times 10^{-15}$ & $\mathrm{~B}$ & $0.02(0.57)$ & $7.4 \times 10^{-11}$ & $\{0.01\}$ & $7.4 \times 10^{-15}$ & $\{4.6\}$ & $(6.4 \pm 0.61) \times 10^{-11}$ & $\{0.01\}$ & $(1.3 \pm 0.22) \times 10^{-14}$ & $\{8.2\}$ \\
\hline & & & $\mathrm{C}$ & 1 & $1.6 \times 10^{-9}$ & $\{0.25\}$ & $1.4 \times 10^{-15}$ & $\{0.86\}$ & $(4.3 \pm 2.2) \times 10^{-10}$ & $\{0.07\}$ & $(1.7 \pm 0.06) \times 10^{-15}$ & $\{1.1\}$ \\
\hline$\cdot \mathrm{BrCl}^{-}$ & $2.2 \times 10^{-9}$ & $1.5 \times 10^{-12}$ & $\mathrm{~B}$ & $0.07(0.57)$ & $3.7 \times 10^{-10}$ & $\{0.17\}$ & $6.6 \times 10^{-12}$ & $\{4.5\}$ & $(3.2 \pm 0.31) \times 10^{-10}$ & $\{0.15\}$ & $(1.2 \pm 0.20) \times 10^{-11}$ & $\{8.2\}$ \\
\hline$(3 B P D)^{f}$ & & & $\mathrm{C}$ & 1 & $7.6 \times 10^{-9}$ & $\{3.5\}$ & $1.3 \times 10^{-12}$ & $\{0.87\}$ & $(2.1 \pm 1.4) \times 10^{-9}$ & $\{0.96\}$ & $(1.5 \pm 0.04) \times 10^{-12}$ & $\{1.1\}$ \\
\hline$\cdot \mathrm{BrCl}^{-}$ & $2.2 \times 10^{-9}$ & $1.5 \times 10^{-12}$ & B & $0.80(0.05)$ & $2.7 \times 10^{-9}$ & $\{1.2\}$ & $1.8 \times 10^{-12}$ & $\{1.2\}$ & $(6.4 \pm 5.0) \times 10^{-9}$ & $\{2.9\}$ & $(1.5 \pm 0.11) \times 10^{-12}$ & $\{0.99\}$ \\
\hline$(3 \mathrm{CPD})^{\mathrm{f}}$ & & & $\mathrm{C}$ & 1 & $5.4 \times 10^{-9}$ & $\{2.4\}$ & $1.4 \times 10^{-12}$ & $\{0.96\}$ & $(8.9 \pm 11) \times 10^{-9}$ & $\{4.0\}$ & $(1.4 \pm 0.14) \times 10^{-12}$ & $\{0.93\}$ \\
\hline \multirow[t]{2}{*}{$\cdot \mathrm{Cl}_{2}^{-}$} & $3.4 \times 10^{-9}$ & $2.0 \times 10^{-15}$ & $\mathrm{~B}$ & $0.09(0.16)$ & $9.8 \times 10^{-12}$ & $\{0.003\}$ & $2.8 \times 10^{-15}$ & $\{1.4\}$ & $(2.3 \pm 1.8) \times 10^{-11}$ & $\{0.007\}$ & $(2.3 \pm 0.18) \times 10^{-15}$ & $\{1.2\}$ \\
\hline & & & $\mathrm{C}$ & 1 & $7.0 \times 10^{-11}$ & $\{0.02\}$ & $1.9 \times 10^{-15}$ & $\{0.95\}$ & $(2.5 \pm 0.01) \times 10^{-11}$ & $\{0.007\}$ & $(2.0 \pm 0.14) \times 10^{-15}$ & $\{1.0\}$ \\
\hline \multirow{2}{*}{$\mathrm{Br}_{2}$} & $4.6 \times 10^{-10}$ & $5.8 \times 10^{-11}$ & B & $0.15(0.06)$ & $8.3 \times 10^{-11}$ & $\{0.18\}$ & $4.9 \times 10^{-11}$ & $\{0.84\}$ & $(7.2 \pm 0.69) \times 10^{-11}$ & $\{0.16\}$ & $(8.8 \pm 1.5) \times 10^{-11}$ & $\{1.5\}$ \\
\hline & & & $\mathrm{C}$ & 1 & $8.4 \times 10^{-11}$ & $\{0.18\}$ & $5.5 \times 10^{-11}$ & $\{0.95\}$ & $(1.0 \pm 0.05) \times 10^{-10}$ & $\{0.22\}$ & $(4.6 \pm 0.59) \times 10^{-11}$ & $\{0.79\}$ \\
\hline $\mathrm{BrCl}$ & $9.6 \times 10^{-11}$ & $3.0 \times 10^{-12}$ & B & $0.76(0.06)$ & $4.6 \times 10^{-10}$ & $\{4.8\}$ & $2.6 \times 10^{-12}$ & $\{0.85\}$ & $(4.0 \pm 0.38) \times 10^{-10}$ & $\{4.1\}$ & $(4.6 \pm 0.76) \times 10^{-12}$ & $\{1.5\}$ \\
\hline$(3 \mathrm{BPD})^{\mathrm{g}}$ & & & $\mathrm{C}$ & 1 & $4.6 \times 10^{-10}$ & $\{4.8\}$ & $2.9 \times 10^{-12}$ & $\{0.96\}$ & $(5.6 \pm 0.24) \times 10^{-10}$ & $\{5.8\}$ & $(2.4 \pm 0.30) \times 10^{-12}$ & $\{0.80\}$ \\
\hline \multirow[t]{2}{*}{$\mathrm{Cl}_{2}$} & $8.8 \times 10^{-13}$ & $1.9 \times 10^{-14}$ & $\mathrm{~B}$ & $0.09(0.58)$ & $1.0 \times 10^{-11}$ & $\{11\}$ & $1.3 \times 10^{-15}$ & $\{0.07\}$ & $(2.4 \pm 2.2) \times 10^{-11}$ & $\{27\}$ & $(1.1 \pm 0.08) \times 10^{-15}$ & $\{0.06\}$ \\
\hline & & & $\mathrm{C}$ & 1 & $4.5 \times 10^{-12}$ & $\{5.1\}$ & $1.9 \times 10^{-14}$ & $\{1.0\}$ & $(3.8 \pm 1.4) \times 10^{-12}$ & $\{4.3\}$ & $(1.7 \pm 0.62) \times 10^{-14}$ & $\{0.89\}$ \\
\hline \multicolumn{13}{|c|}{ Experiment $\# 3\left(\left[\mathrm{Cl}^{-}\right]=0.56 \mathrm{M},\left[\mathrm{Br}^{-}\right]=0.80 \mathrm{mM}, \mathrm{pH}=5.5\right)$} \\
\hline \multirow[t]{2}{*}{$\mathrm{Br}^{\bullet}$} & $6.3 \times 10^{-9}$ & $1.6 \times 10^{-15}$ & $\mathrm{~B}$ & $0.22(0.08)$ & $6.1 \times 10^{-10}$ & $\{0.10\}$ & $1.8 \times 10^{-15}$ & $\{1.1\}$ & $(3.4 \pm 0.50) \times 10^{-10}$ & $\{0.05\}$ & $(3.7 \pm 0.26) \times 10^{-15}$ & $\{2.3\}$ \\
\hline & & & $\mathrm{C}$ & 1 & $1.1 \times 10^{-9}$ & $\{0.18\}$ & $1.6 \times 10^{-15}$ & $\{0.97\}$ & $(5.2 \pm 0.91) \times 10^{-10}$ & $\{0.08\}$ & $(3.1 \pm 0.17) \times 10^{-15}$ & $\{1.9\}$ \\
\hline$\cdot \mathrm{BrCl}^{-}$ & $6.2 \times 10^{-9}$ & $1.5 \times 10^{-12}$ & B & $0.66(0.08)$ & $3.1 \times 10^{-9}$ & $\{0.50\}$ & $1.7 \times 10^{-12}$ & $\{1.1\}$ & $(1.7 \pm 0.25) \times 10^{-9}$ & $\{0.28\}$ & $(3.4 \pm 0.23) \times 10^{-12}$ & $\{2.3\}$ \\
\hline$(3 \mathrm{BPD})^{\mathrm{f}}$ & & & $\mathrm{C}$ & 1 & $5.6 \times 10^{-9}$ & $\{0.90\}$ & $1.5 \times 10^{-12}$ & $\{0.97\}$ & $(2.6 \pm 0.47) \times 10^{-9}$ & $\{0.42\}$ & $(2.8 \pm 0.17) \times 10^{-12}$ & $\{1.9\}$ \\
\hline$\cdot \mathrm{BrCl}^{-}$ & $6.2 \times 10^{-9}$ & $1.5 \times 10^{-12}$ & B & $0.95(<0.01)$ & $4.2 \times 10^{-9}$ & $\{0.68\}$ & $1.5 \times 10^{-12}$ & $\{0.98\}$ & $(2.6 \pm 1.6) \times 10^{-9}$ & $\{0.41\}$ & $(1.3 \pm 0.08) \times 10^{-12}$ & $\{0.85\}$ \\
\hline$(3 \mathrm{CPD})^{\mathrm{f}}$ & & & $\mathrm{C}$ & 1 & $5.6 \times 10^{-9}$ & $\{0.90\}$ & $1.5 \times 10^{-12}$ & $\{0.99\}$ & $(3.4 \pm 2.4) \times 10^{-9}$ & $\{0.54\}$ & $(1.3 \pm 0.12) \times 10^{-12}$ & $\{0.86\}$ \\
\hline \multirow[t]{2}{*}{$\cdot \mathrm{Cl}_{2}^{-}$} & $4.4 \times 10^{-11}$ & $9.2 \times 10^{-16}$ & B & $0.04(0.02)$ & $5.8 \times 10^{-12}$ & $\{0.13\}$ & $8.9 \times 10^{-16}$ & $\{0.96\}$ & $(3.6 \pm 2.2) \times 10^{-12}$ & $\{0.08\}$ & $(7.8 \pm 0.50) \times 10^{-16}$ & $\{0.84\}$ \\
\hline & & & $\mathrm{C}$ & 1 & $8.0 \times 10^{-12}$ & $\{0.18\}$ & $8.9 \times 10^{-16}$ & $\{0.96\}$ & $(4.5 \pm 3.4) \times 10^{-12}$ & $\{0.10\}$ & $(7.8 \pm 0.69) \times 10^{-16}$ & $\{0.85\}$ \\
\hline \multirow[t]{2}{*}{$\mathrm{Br}_{2}$} & $2.6 \times 10^{-11}$ & $3.6 \times 10^{-13}$ & B & $0.02(0.58)$ & $8.7 \times 10^{-12}$ & $\{0.34\}$ & $1.5 \times 10^{-13}$ & $\{0.42\}$ & $(4.9 \pm 0.71) \times 10^{-12}$ & $\{0.19\}$ & $(3.1 \pm 0.21) \times 10^{-13}$ & $\{0.86\}$ \\
\hline & & & $\mathrm{C}$ & 1 & $4.7 \times 10^{-12}$ & $\{0.18\}$ & $3.8 \times 10^{-13}$ & $\{1.1\}$ & $(4.4 \pm 0.67) \times 10^{-12}$ & $\{0.17\}$ & $(1.1 \pm 0.80) \times 10^{-12}$ & $\{3.0\}$ \\
\hline $\mathrm{BrCl}$ & $1.2 \times 10^{-12}$ & $1.9 \times 10^{-14}$ & $\mathrm{~B}$ & $0.09(0.59)$ & $4.8 \times 10^{-11}$ & $\{40\}$ & $7.9 \times 10^{-15}$ & $\{0.42\}$ & $(2.7 \pm 0.39) \times 10^{-11}$ & $\{22\}$ & $(1.6 \pm 0.11) \times 10^{-14}$ & $\{0.86\}$ \\
\hline & & & $\mathrm{C}$ & 1 & $2.5 \times 10^{-11}$ & $\{21\}$ & $2.0 \times 10^{-14}$ & $\{1.1\}$ & $(2.4 \pm 0.36) \times 10^{-11}$ & $\{20\}$ & $(5.8 \pm 4.3) \times 10^{-14}$ & $\{3.1\}$ \\
\hline \multicolumn{13}{|c|}{ Experiment \#4 ([Cl- $\left.]=0.56 \mathrm{M},\left[\mathrm{Br}^{-}\right]=0.80 \mathrm{mM}, \mathrm{pH}=8.0\right)$} \\
\hline $\mathrm{Br}^{\bullet}$ & $4.5 \times 10^{-9}$ & $1.2 \times 10^{-15}$ & B & $0.998(<0.01)$ & $7.5 \times 10^{-10}$ & $\{0.17\}$ & $1.1 \times 10^{-15}$ & $\{0.99\}$ & $(5.3 \pm 0.62) \times 10^{-10}$ & $\{0.12\}$ & $(6.6 \pm 0.11) \times 10^{-16}$ & $\{0.57\}$ \\
\hline & & & $\mathrm{C}$ & 1 & $1.0 \times 10^{-9}$ & $\{0.23\}$ & $1.1 \times 10^{-15}$ & $\{0.99\}$ & $(7.2 \pm 0.86) \times 10^{-10}$ & $\{0.16\}$ & $(6.6 \pm 0.11) \times 10^{-16}$ & $\{0.57\}$ \\
\hline$\cdot \mathrm{BrCl}^{-}$ & $6.3 \times 10^{-9}$ & $1.1 \times 10^{-12}$ & $\mathrm{~B}$ & $0.95(<0.01)$ & $3.9 \times 10^{-9}$ & $\{0.62\}$ & $1.0 \times 10^{-12}$ & $\{0.99\}$ & $(1.5 \pm 0.28) \times 10^{-9}$ & $\{0.23\}$ & $(1.0 \pm 0.22) \times 10^{-12}$ & $\{0.98\}$ \\
\hline$(3 \mathrm{CPD})^{\mathrm{f}}$ & & & $\mathrm{C}$ & 1 & $5.3 \times 10^{-9}$ & $\{0.85\}$ & $1.0 \times 10^{-12}$ & $\{0.98\}$ & $(2.0 \pm 0.39) \times 10^{-9}$ & $\{0.32\}$ & $(1.0 \pm 0.22) \times 10^{-12}$ & $\{0.97\}$ \\
\hline$\cdot \mathrm{Cl}_{2}^{-}$ & $2.0 \times 10^{-11}$ & $6.4 \times 10^{-16}$ & B & $0.04(<0.01)$ & $5.3 \times 10^{-12}$ & $\{0.26\}$ & $6.2 \times 10^{-16}$ & $\{0.97\}$ & $(2.0 \pm 0.38) \times 10^{-12}$ & $\{0.10\}$ & $(6.1 \pm 1.3) \times 10^{-16}$ & $\{0.96\}$ \\
\hline & & & $\mathrm{C}$ & 1 & $7.4 \times 10^{-12}$ & $\{0.37\}$ & $6.1 \times 10^{-16}$ & $\{0.96\}$ & $(2.8 \pm 0.55) \times 10^{-12}$ & $\{0.14\}$ & $(6.0 \pm 1.3) \times 10^{-16}$ & $\{0.94\}$ \\
\hline
\end{tabular}

Lifetimes $\left(\tau_{i}\right)$ were not included in the table but can be calculated as $\tau_{i}=[i] / R_{F}^{i}$. Values of (MVDT/Exp) for $\tau_{i}$ are calculated by dividing the (MVDT/Exp) value for [ $i]$ by the (MVDT/Exp) value for $R_{F}^{i}$. The values for (EVDT/Exp) for $\tau_{i}$ are calculated in an analogous manner. ${ }^{a}$ Expected values are model-derived best estimates of the actual values for [i] and $R_{F}^{i}$ in the experimental solutions in the absence of AA (Sect. 3.4).

${ }^{\mathrm{b}}$ Data treatments (D.T.) are discussed in Sect. 3.5. Data treatment B makes a rough correction for the $F_{i}^{3 X P D}$ effect, while data treatment C makes corrections for both the AA and $F_{i}^{3 X P D}$ effects.

c Values in parentheses are the relative standard deviations of the average $F_{i}^{3 \mathrm{XPD}}$ values calculated for the linear AA ranges (Table 1). Treatments B and $\mathrm{C}$ rely on the inverse plot defined by the linear AA range.

d Calculated by taking the model-derived "data" through the data treatment steps (Sect. 3.5).

e Calculated by taking the experimental results through the data treatment steps (Sect. 3.6). Errors are \pm 1 standard error calculated based on the standard errors of the slope and y-intercept from the inverse plots.

${ }^{\mathrm{f}}$ Kinetic information for ${ }^{\bullet} \mathrm{BrCl}^{-}$can be determined using the inverse plot generated with either the 3BPD or 3CPD data. The analyte listed in parentheses is the one used for a given set of kinetic information.

$\mathrm{g}$ Kinetic information for $\mathrm{BrCl}$ is determined using inverse plots generated from 3BPD data since $\mathrm{BrCl}$ is not a significant source of 3CPD.

\subsection{Competition kinetics: overview and expected values}

As described in Part 1, we use the competition kinetics experiments to calculate the steady-state concentration ([i]), rate of formation $\left(R_{F}^{i}\right)$, and lifetime $\left(\tau_{i}\right)$ for each reactive halogen species $i$. Here we apply these techniques for four experiments conducted with the chloride and mixed halide systems. Below we discuss how we use model "data" to test our kinetic equations (and associated data treatments) for determining $[i], R_{F}^{i}$, and $\tau_{i}$, and how we use experimental data to test the overall probe method.

In order to evaluate the validity of our kinetic Eqs. (14-16) with model "data", we need to first determine the "expected" values of $[i], R_{F}^{i}$, and $\tau_{i}$ for each reactive halogen species in our competition kinetics experiments (Table 1). We obtain 
expected values for $[i]$ directly from the Mix Full Model using the same conditions (e.g., $\mathrm{pH},\left[\mathrm{Br}^{-}\right],\left[\mathrm{Cl}^{-}\right]$) as the corresponding experiment except that $[\mathrm{AA}]$ is set to zero.

As in Part 1, expected values of $R_{F}^{i}$ in the chloride and mixed halide experiments are based on kinetic equations derived from the reactions responsible for the formation of $i$ (S.8 and S.9). For example, the rates of formation of ${ }^{\bullet} \mathrm{Cl}_{2}^{-}$ and $\mathrm{Cl}^{\bullet}$ in the chloride and mixed halide systems are calculated using

$R_{F}^{\mathrm{Cl}_{2}^{-}}=k_{\mathrm{Cl}^{-}}^{\mathrm{ClOH}^{-}}\left[\mathrm{Cl}^{-}\right]\left[{ }^{\bullet} \mathrm{ClOH}^{-}\right]+k_{\mathrm{H}^{+}}^{\mathrm{ClOH}^{-}}\left[{ }^{\bullet} \mathrm{ClOH}^{-}\right]\left[\mathrm{H}^{+}\right](\mathrm{S} 36)$

$R_{F}^{\mathrm{Cl}}=k_{\mathrm{OH}}^{\mathrm{Cl}^{-}}\left[{ }^{\bullet} \mathrm{OH}\right]\left[\mathrm{Cl}^{-}\right] Y_{\mathrm{OH}}^{\mathrm{Cl}}$

In the case of $\mathrm{BrCl}^{-}$the formation rate is calculated using

$\left.\left.R_{F}^{\mathrm{BrCl}^{-}}=k_{\mathrm{BrOH}^{-}}^{\mathrm{Cl}^{-}}{ }^{\bullet} \mathrm{BrOH}^{-}\right]\left[\mathrm{Cl}^{-}\right]+k_{\mathrm{ClOH}^{-}}^{\mathrm{Br}^{-}}{ }^{\bullet} \mathrm{ClOH}^{-}\right]\left[\mathrm{Br}^{-}\right](\mathrm{S} 38)$

Instead of directly calculating rates of formation of $\mathrm{Br}^{\bullet}, \mathrm{Br}_{2}$, $\mathrm{Cl}_{2}$, and $\mathrm{BrCl}$ in the mixed halide system, we use their overall rates of destruction with the major sinks $\left(\mathrm{H}_{2} \mathrm{O}_{2}, \mathrm{HO}_{2}^{*}\right.$, and $\mathrm{O}_{2}^{-}$). This approach works since these species are all at steady state (thus, for a given species, the formation and destruction rates are equivalent) and is simpler since the formation rates are difficult to determine (Matthew, 2002). However, because of the complexity of the mixed halide system and the fact that a number of the mixed halide species undergo rapid interconversions, the expected values for the rates of formation should be considered estimates. Finally, the expected value for the lifetime of each reactive halogen species is calculated from

$\tau_{i}=\frac{[i]}{R_{F}^{i}}$

3.5 Competition kinetics: model experiments and data treatments

In Part 1 we evaluated our kinetic equations and three data treatments (A, B, and C) for their ability to provide accurate results for $[i], R_{F}^{i}$, and $\tau_{i}$ in bromide solutions. Treatment $\mathrm{A}$ is not used here because it is only applicable for $\mathrm{Br}^{\bullet}$ in solutions containing only bromide (Part 1). Data treatments B and $\mathrm{C}$ are first evaluated here by applying the treatments to "data" generated from model simulations (i.e., model "experiments") performed under the same conditions as the actual competition kinetics experiments (Table 1). We evaluate these data treatments by comparing the results obtained from the model "data" after data treatment (i.e., MVDT values; Table 2) with the expected values described above. Because - $\mathrm{BrCl}^{-}$can form both 3BPD and 3CPD (Table S5), MVDT values of $[i], R_{F}^{i}$, and $\tau_{i}$ for ${ }^{\bullet} \mathrm{BrCl}^{-}$can be obtained from both the 3BPD and 3CPD inverse plots. Note that species that are insignificant sources of 3XPD (e.g., $\mathrm{Cl}^{\bullet}$ in the mixed halide solutions) are not evaluated.
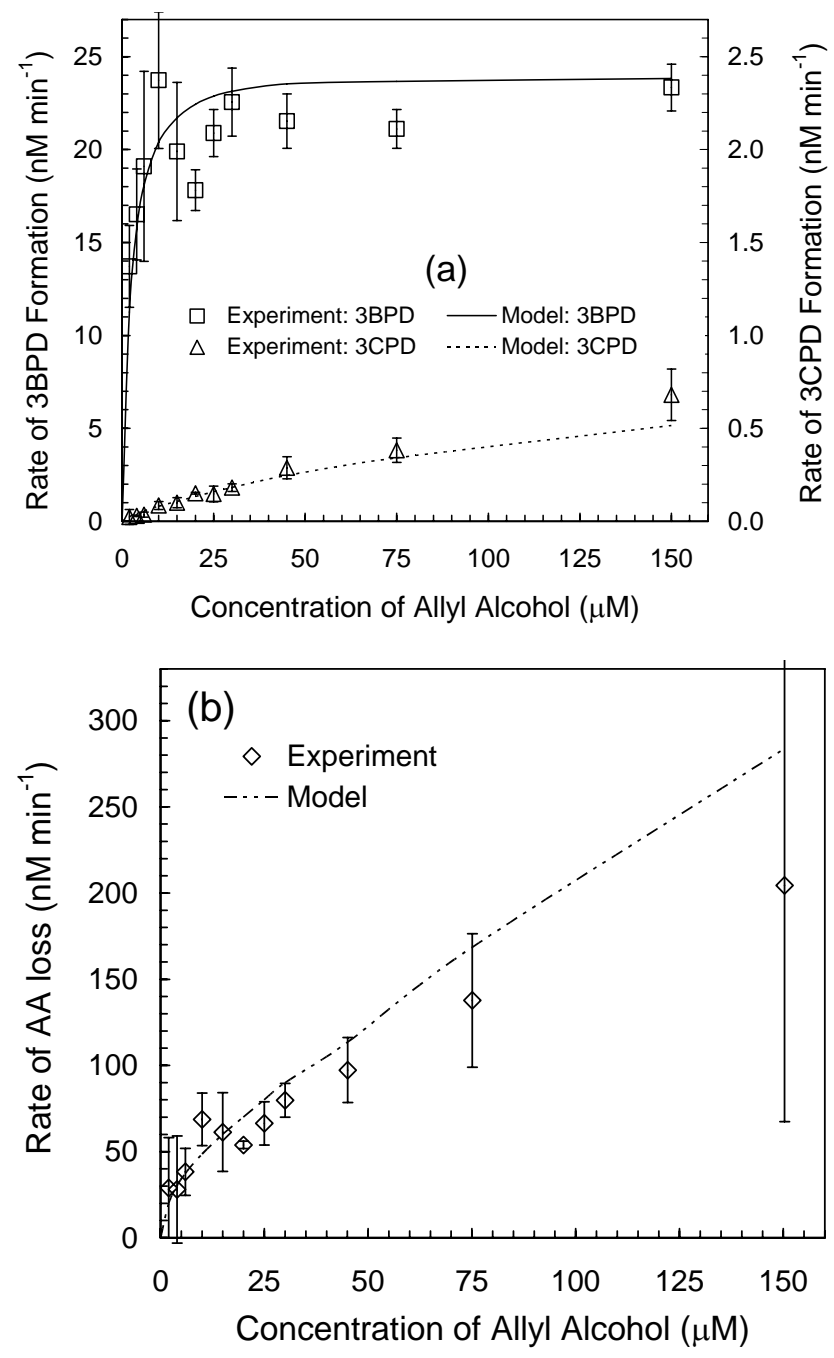

Fig. 5. (a) Rates of 3-bromo-1,2-propane-diol (3BPD) and 3chloro-1,2-propanediol (3CPD) formation $\left(R_{F}^{3 \mathrm{BPD}}\right.$, tot and $\left.R_{F \text {, tot }}^{3 \mathrm{CPD}}\right)$ as a function of [AA] in illuminated $(313 \mathrm{~nm})$ aqueous halide solutions $\left(\left[\mathrm{Cl}^{-}\right]=0.56 \mathrm{M},\left[\mathrm{Br}^{-}\right]=0.80 \mathrm{mM}\right.$, and $\left.\mathrm{pH} 3.0\right)$ containing $1.0 \mathrm{mM}$ $\mathrm{H}_{2} \mathrm{O}_{2}$. The symbols and error bars are the same as in Fig. 3a. (b) Rates of allyl alcohol loss $\left(R_{L}^{\mathrm{AA}}\right)$ in the experiments described in Fig. 5a. The symbols and error bars are the same as in Fig. 3b.

3.5.1 Evaluation of data treatment B using data generated from model experiments

As discussed in Part 1 (Sect. 3.6.2), data treatment B involves fitting a line to the linear portion of the inverse plot and using the resulting slope and y-intercept (i.e., $b^{\prime}$ and $a^{\prime}$ ) in Eqs. $14-16$ to calculate $[i], R_{F}^{i}$, and $\tau_{i}$. This treatment includes a rough adjustment for the " $F_{i}^{3 X P D}$ effect" by including $F_{i}^{3 X P D}$ in these equations, but no correction for the "AA effect". Values for $F_{i}^{3 \mathrm{XPD}}$ are obtained from the model runs (see Sect. 2.3) and are averages over the linear ranges (Table 2). 


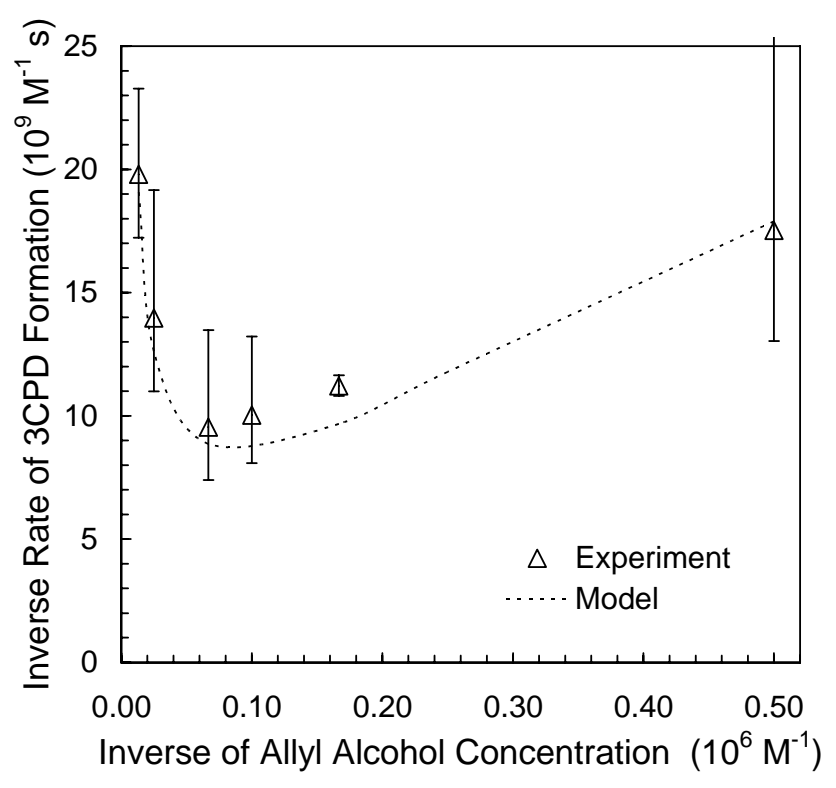

Fig. 6. Inverse plot for the chloride competition kinetics experiment described in Table 1 (Experiment 1) and Fig. $2 \mathrm{a}\left(\left[\mathrm{Cl}^{-}\right]=0.56 \mathrm{M}, \mathrm{pH}\right.$ 5.4). The triangles are the inverse of the experimentally determined rates of 3CPD formation and the dotted line shows the corresponding results from the $\mathrm{Cl}^{-}$Full Model. Error bars represent $90 \%$ confidence intervals around the experimental data.

In the chloride solution (experiment \#1; Table 1 ), ${ }^{\bullet} \mathrm{Cl}_{2}^{-}$ dominates the formation of 3CPD. The value for $\left[{ }^{\bullet} \mathrm{Cl}_{2}^{-}\right] \mathrm{ob}-$ tained from treatment B is within $20 \%$ of the expected value, while values for $R_{F}^{\mathrm{Cl}_{2}^{-}}$and $\tau_{\mathrm{Cl} 2}$ - are within a factor of 2.5 of their expected values (Table 2). Treatment B does a poor job for the $\mathrm{Cl}^{\bullet}$ kinetics, but this is not surprising since $\mathrm{Cl}^{\bullet}$ accounts for a very small (and highly variable) portion of 3CPD formation $\left(F_{i}^{3 \mathrm{XPD}}=0.03, \mathrm{RSD}=37 \%\right.$; Table 2$)$.

Using treatment $\mathrm{B}$ on output from models run using the conditions in the mixed halide solutions yields values of [i] that are within $20 \%$ of the expected values for species that are significant sources of $3 \mathrm{XPD}$ (i.e., $F_{i}^{3 \mathrm{XPD}} \geq 0.15$; Experiments 2-4, Table 2). When $F_{i}^{3 \mathrm{XPD}}$ values are less than 0.15 , differences in $[i]$ are generally larger, although there are several exceptions (e.g., ${ }^{\bullet} \mathrm{Cl}_{2}^{-}$). Under conditions where $F_{i}^{3 \mathrm{XPD}} \geq 0.95$, MVDT (model output with data treatment) results for $[i]$ are within $5 \%$ of the expected values. In contrast to these steady-state concentration results, model derived formation rates and lifetimes with Treatment B generally do not agree with the calculated expected values. One exception is - $\mathrm{BrCl}^{-}$, which is generally within a factor of two of expected values. In part this overall poor agreement might be due to the difficulty of calculating expected values for $R_{F}^{i}$ in mixed halide solutions (Sect. 3.4).
3.5.2 Evaluation of data treatment $\mathrm{C}$ using data generated from model experiments

While treatment $\mathrm{C}$ also involves fitting a line to the linear portion of the inverse plot (like treatment B), it is different in that it includes considerable effort to correct for both the AA and $F_{i}^{3 X P D}$ effects. As shown in Table 2, treatment $\mathrm{C}$ gives very good results for ${ }^{\bullet} \mathrm{Cl}_{2}^{-}$in the chloride experiment, with MVDT values for [i], $R_{F}^{i}$, and $\tau_{i}$ that are within $16 \%, 10 \%$, and $24 \%$, respectively, of the expected values. Treatment $\mathrm{C}$ could not be used for $\mathrm{Cl}^{\bullet}$ because the linear portion of the inverse plot of $R_{F, C l}^{3 C P D}$ (the rate of 3CPD formation due to $\mathrm{Cl}^{\bullet}$ ) had a negative slope, due to the fact that $\mathrm{Cl}^{\bullet}$ contributed very little to $3 \mathrm{CPD}$ formation.

For all species in the mixed halide system, treatment $\mathrm{C}$ produces MVDT values of [i] that are always within $30 \%$ (and often within 10\%) of the expected values, regardless of the size of $F_{i}^{3 \mathrm{XPD}}$. Although treatment $\mathrm{C}$ provides good results for $[i]$ for all species, it does a poor job of determining $R_{F}^{i}$ and $\tau_{i}$. The exception is ${ }^{\bullet} \mathrm{BrCl}^{-}$at $\mathrm{pH} 5.5$ and 8.0, where MVDT values are within $15 \%$ of expected values (Table 2). Overall, MVDT results for $[i], R_{F}^{i}$, and $\tau_{i}$ from treatment $\mathrm{C}$ are almost always better than those from data treatment B, but in general only the steady-state concentrations are reliably close to the expected values. As described above, given the complexity of the mixed halide system, it is possible that the large differences between the expected and modeled (MVDT) results for $R_{F}^{i}$ (and $\tau_{i}$ ) obtained with treatment $\mathrm{C}$ might be because of errors in the expected values.

\subsection{Competition kinetics: experimental data}

In this section we use the experimental data generated in the competition kinetics experiments (i.e., $R_{F}^{3 \mathrm{XPD}}$ as a function of [AA]; Sects. 3.2.2 and 3.3.3) to evaluate the overall chemical probe technique. We do this by comparing the experimentally derived results for $[i], R_{F}^{i}$, and $\tau_{i}$ (i.e., EVDT results; Table 2) with the model-derived expected values (Sect. 3.4). The conditions for the four experiments are listed in Table 1. As described in Part 1, it should be kept in mind that the model experiments establish an upper limit of method performance that cannot be exceeded by experimental results. The few cases where EVDT values are closer to the expected values than MVDT values are probably due to experimental error.

3.6.1 Kinetic results from the chloride experiment (Experiment 1)

The inverse plot for the chloride competition kinetics experiment (Sect. 3.2.2) is shown in Fig. 6, along with the corresponding results from the $\mathrm{Cl}^{-}$Full Model. Based on the model results, ${ }^{\bullet} \mathrm{Cl}_{2}^{-}$represents nearly all $(97 \%)$ of 3CPD formation over the linear range of the inverse plot (Table 2). Data treatment $\mathrm{C}$ produces the best results from 
the experimental values, in agreement with the model results. With this treatment experimentally derived values of $[i], R_{F}^{i}$ and $\tau_{i}$ for ${ }^{\bullet} \mathrm{Cl}_{2}^{-}$are within $20 \%, 35 \%$, and $46 \%$, respectively, of the expected values (Table 2). When treatment $\mathrm{B}$ is used, the experimental value for $\left[{ }^{\bullet} \mathrm{Cl}_{2}^{-}\right]$is within $10 \%$ of the expected value, but $R_{F}^{i}$ and $\tau_{i}$ are off by a factor of 3-4 (Table 2). Because $\mathrm{Cl}^{\bullet}$ accounts for an average of only $3 \%$ of the 3CPD formed, treatment $\mathrm{B}$ with the experimental data yields $\mathrm{Cl}^{\bullet}$ kinetic values that are very poor (as with the MVDT results), while treatment $C$ could not be used.

\subsubsection{Kinetic results for the mixed halide experiments (Ex- periments 2-4)}

Competition kinetics experiments in mixed halide solutions were conducted at $\mathrm{pH} 3.0,5.5$ and 8.0 (Table 2). As summarized in Table 1, in all three cases there is good agreement between the model and experimental results, with average RPD values for $1 / R_{F, \text { tot }}^{3 X P D}$ of $10-50 \%$. As an example of the good agreement, inverse plots for 3BPD and 3CPD at $\mathrm{pH}$ 3.0 , along with the corresponding model results, are shown in Figs. 7a and b.

In agreement with results from the model data, the allyl alcohol chemical probe technique with treatment B can provide good results for $[i]$ and works best when $F_{i}^{3 \mathrm{XPD}}$ is large. Treatment $\mathrm{C}$ is generally better, producing fair to excellent experimental measurements of the steady-state concentrations of $\mathrm{X}^{*}(\mathrm{aq})$ even in a number of cases where $F_{i}^{3 \mathrm{XPD}}$ is small (Table 2). With one exception $\left({ }^{\bullet} \mathrm{BrCl}^{-}\right.$from 3BPD in Experiment 3), experimental values of $\left[{ }^{\circ} \mathrm{BrCl}^{-}\right]$and $\left[{ }^{\circ} \mathrm{Cl}_{2}^{-}\right]$ obtained with treatment $\mathrm{C}$ are within $20 \%$ of the expected values, while values for $\left[\mathrm{Br}^{\bullet}\right]$ are within a factor of two. The accuracy of the EVDT results for $\left[\mathrm{Br}_{2}\right]$ and $[\mathrm{BrCl}]$ depend on the fraction of 3BPD formed from each of these species. For instance, at $\mathrm{pH} 3.0$ (Experiment 2), $\mathrm{BrCl}$ and $\mathrm{Br}_{2}$ are significant sources of $3 \mathrm{BPD}\left(F_{i}^{3 \mathrm{BPD}}=0.76\right.$ and 0.15 , respectively) and experimental values of $[i]$ (with treatment $C$ ) are within approximately $20 \%$ of the expected values for these two species. However, at $\mathrm{pH} 5.5$ neither $\mathrm{BrCl}$ nor $\mathrm{Br}_{2}$ are significant sources of 3BPD $\left(F_{\mathrm{BrCl}}^{3 \mathrm{BPD}}\right.$ and $F_{\mathrm{Br}_{2}}^{3 \mathrm{BPD}}=0.09$ and 0.02 , respectively) and the experimental values of $[\mathrm{BrCl}]$ and $\left[\mathrm{Br}_{2}\right]$ (with treatment $\mathrm{C}$ ) are higher than the expected values by factors of 3.1 and 3.0, respectively. Note that although data treatment $\mathrm{B}$ appears better than treatment $\mathrm{C}$ for EVDT values for $[\mathrm{BrCl}]$ and $\left[\mathrm{Br}_{2}\right]$ at $\mathrm{pH} 5.5$, the model results (MVDT) indicate that data treatment $\mathrm{C}$ should provide better concentrations (Table 2).

As seen above for the model results, the experimental technique generally does a poor job of measuring $R_{F}^{i}$ (and $\tau_{i}$ ) in mixed halide solutions. The exception is ${ }^{\bullet} \mathrm{BrCl}^{-}$at $\mathrm{pH} 5.5$ and 8.0, where experimentally derived formation rates obtained with data treatment $\mathrm{C}$ are within $15 \%$ of the expected values (Table 2).
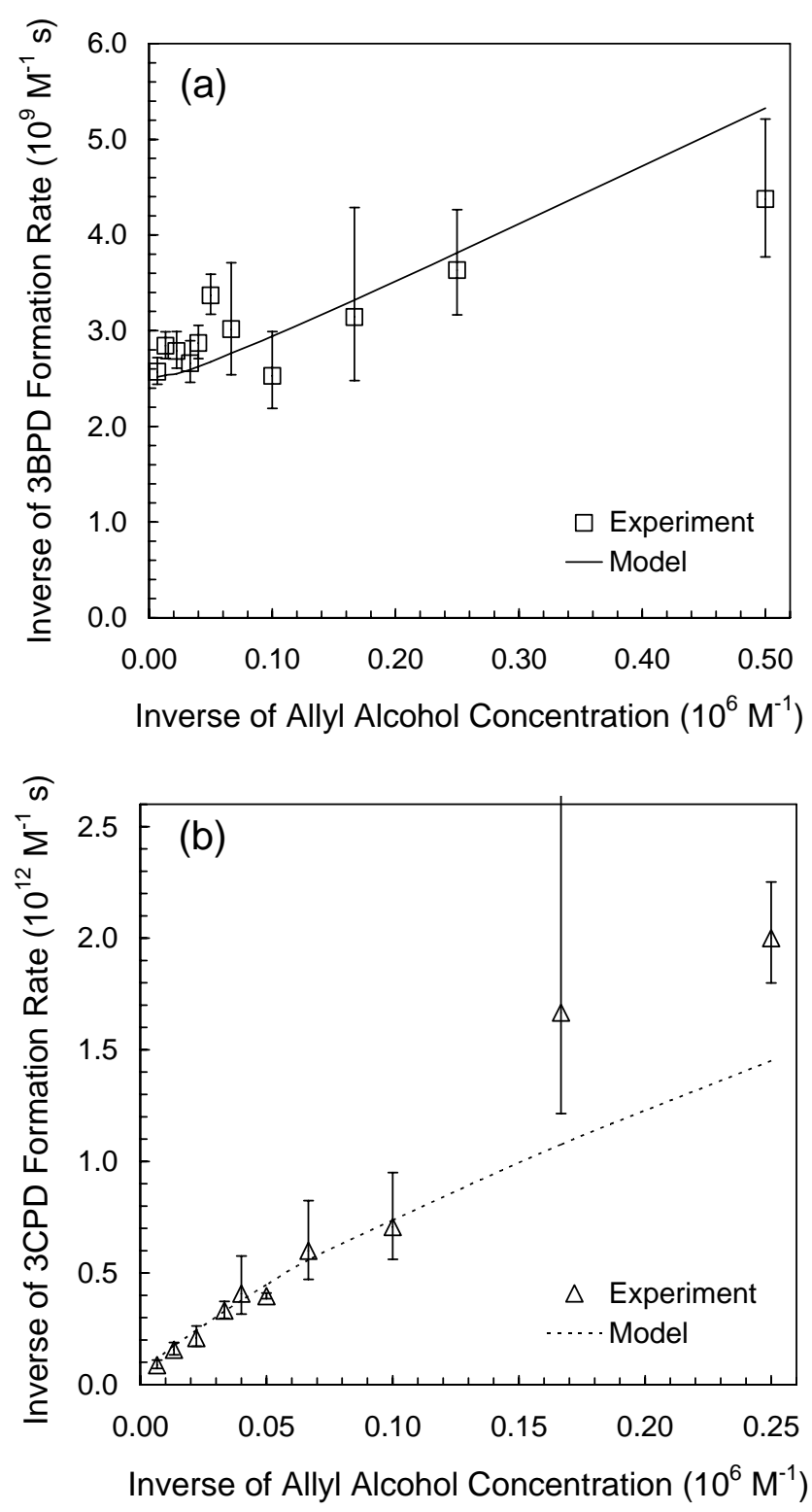

Fig. 7. (a) Inverse plot of $3 \mathrm{BPD}$ for the mixed halide competition kinetics experiment at $\mathrm{pH} 3.0\left(0.56 \mathrm{M} \mathrm{Cl}^{-}, 0.80 \mathrm{mM} \mathrm{Br}^{-}\right.$; Experiment 2 in Table 1 and Fig. 5a). The open squares are the inverse of the experimental rate of 3BPD formation, and the solid line is the inverse of the rate of 3BPD formation from the Mix Full Model. Error bars represent $90 \%$ confidence intervals. (b) Inverse plot of 3CPD from the experiments described in Fig. 7a. The triangles are the inverse of the experimental rates of 3CPD formation, while the dotted line is the corresponding result from the Mix Full Model. Error bars represent $90 \%$ confidence intervals.

3.6.3 Summary of competition kinetic experiments and overall technique

The results of these experiments indicate that the allyl alcohol chemical probe technique, in conjunction with 
competition kinetics and data treatment $\mathrm{C}$, can accurately measure steady-state concentrations of a number of reactive halogen species in mixed halide solutions. These values are nearly all within a factor of 2 of expected values and are often within $20 \%$. The simpler treatment B also generally produces good results for [i] that are within a factor of 2.5 of expected values for those reactive halogens responsible for a significant fraction of the 3XPD measured. In contrast, both treatments produce experimentally determined rates of formation and lifetimes of reactive halogens in mixed halide solutions that are generally quite different from the expected values. This is in contrast to results from solutions containing only bromide (Part 1) or chloride (Sect. 3.6.1), where the technique can generally measure $[i], R_{F}^{i}$, and $\tau_{i}$ to within a factor of 2 for $\mathrm{Br}^{\bullet}, \mathrm{Br}_{2}, \mathrm{HOBr}$, and ${ }^{\bullet} \mathrm{Cl}_{2}^{-}$.

\subsection{Applications and limitations of the probe technique}

As discussed in Part 1, this technique was developed so that we could eventually investigate halide oxidation by ${ }^{\bullet} \mathrm{OH}$ in environmental samples, a process that is important in seawater (Zafiriou et al., 1987; Zhou and Mopper, 1990), sea-salt particles (Matthew et al., 2003), and perhaps in the snowpack (Chu and Anastasio, 2005). As with the bromide system, accurately modeling the chemistry in the chloride and mixed halide systems requires measuring ${ }^{\bullet} \mathrm{OH}$ kinetics in the sample so that $R_{F}^{\mathrm{OH}}$, [$\left.{ }^{\bullet} \mathrm{OH}\right]$, and $\tau_{\mathrm{OH}}$ can be accurately represented in the model. If other oxidants are employed (e.g., $-\mathrm{NO}_{3}$ or $\mathrm{O}_{3}$ ) the kinetic equations and model would need to be modified and tested.

While the work described here was done on laboratory solutions, our technique is sensitive enough that it should also work on environmental samples, although we have not yet performed these experiments. Concentrations of ${ }^{\bullet} \mathrm{OH}$ in the mixed halide solutions (in the absence of AA) in the competition kinetics experiments here ranged from (4-9) $\times 10^{-16} \mathrm{M}$. Based on the sensitive detection limits for 3BPD and 3CPD (approximately 1 and $7 \mathrm{nM}$, respectively; Matthew and Anastasio, 2000), the technique should work readily in illuminated sea-salt aerosols where ${ }^{\bullet} \mathrm{OH}$ concentrations are typically $10^{-16}-10^{-15} \mathrm{M}$ (Newberg, 2003). After some modification to improve sensitivity (e.g., by taking larger sample aliquots), the technique should also be useful in illuminated seawater samples where hydroxyl radical concentrations are typically $10^{-18}$ to $10^{-17} \mathrm{M}$ (Zhou and Mopper, 1990). In addition to quantifying concentrations of reactive halogens in environmental samples, the technique also offers the opportunity to quantitatively examine the rates and mechanisms of halogenation of organic compounds under environmental conditions.

The major limitation of the method stems from the fact that it is somewhat nonspecific, i.e., 3BPD and 3CPD are each formed by several different reactive halogen species. Because of this, we need to use results from a numerical model to calculate the fraction of 3XPD formed from each species $\left(F_{i}^{3 \mathrm{XPD}}\right)$. There are possible biases associated with using these model-derived values of $F_{i}^{3 \mathrm{XPD}}$, but as discussed in Part 1, we feel these biases are generally small. In addition, there are some important conditions (e.g., at the high $\mathrm{pH}$ of seawater or fresh sea-salt particles; see Experiment 4 in Table 2) where 3XPD is formed by essentially only one species and thus the lack of specificity in the technique is unimportant.

A second limitation of the technique is that a data treatment must be chosen to analyze the experimental results. In the well-defined laboratory solutions studied here we can choose data treatments based on their performance in the model experiments (Sect. 3.5). Similar steps could be performed for studies of environmental samples, but this would assume that results from the laboratory solutions are generally applicable to environmental samples. A third limitation of the technique in mixed halide solutions is that it can currently only be used to quantitatively measure steadystate concentrations of $\mathrm{X}^{*}(\mathrm{aq})$, with the exception of $\bullet \mathrm{BrCl}^{-}$ in non-acidic solutions where $R_{F}^{i}$ and $\tau_{i}$ can also be determined. Finally, one additional limitation is that our kinetic modeling relies, in part, on rate constants that were estimated based on fitting the model to our experimental results. While we used independently measured reactions and rate constant where possible, there are currently very few published reports about mixed halide radical reactions, or the reactions of reactive halogens with unsaturated organic compounds, in aqueous solution. As new data become available they should improve both the predictive power of the kinetic model as well as the accuracy of the chemical probe technique.

\section{Conclusions}

We have developed a chemical probe technique that can quantify reactive halide species in solutions containing bromide and/or chloride. This technique is based on the reaction of aqueous-phase reactive halogens $\left(\mathrm{X}^{*}(\mathrm{aq})\right)$ with allyl alcohol to form 3-bromo-1, 2-propanediol and 3-chloro-1, 2propanediol (collectively referred to as 3XPD). Using competition kinetics, the measured rates of 3XPD formation are used to determine the steady-state concentrations of $X^{*}(\mathrm{aq})$ as well as their rates of formation and lifetimes under some conditions. The technique was in part validated with models that were constrained by several sets of experiments that measured 3XPD formation and $\mathrm{Br}_{2}(\mathrm{~g})$ release under a wide range of experimental conditions.

In bromide or chloride solutions the technique can be used to measure steady- state concentrations, rates of formation, and lifetimes of several reactive halide species, including $\mathrm{Br}^{\bullet}, \mathrm{Br}_{2}, \mathrm{HOBr}$, and ${ }^{\bullet} \mathrm{Cl}_{2}^{-}$. In mixed bromide/chloride solutions, the technique can measure steady-state concentrations of these same species as well as $\mathrm{BrCl}$ and ${ }^{\bullet} \mathrm{BrCl}^{-}$. Experimentally determined results are generally within a factor of 2-3 (and often much closer) of values derived from model 
runs. While this technique has a few limitations, it is a new and sensitive tool that can be used to investigate aqueous halide chemistry, halide oxidation mechanisms and halide radical dynamics in both laboratory solutions and environmental samples.

Acknowledgements. This work was supported by the Atmospheric Chemistry Program of the National Science Foundation (ATM-9701995), a NASA Earth System Science Fellowship (to B. M. Matthew), and by a University of California, Davis Jastro-Shields Fellowship. The authors thank A. Jordan, J. Chang, J. Smith, and I. George for assistance.

Edited by: M.Ammann

\section{References}

Anastasio, C., Faust, B. C., and Allen, J. M.: Aqueous phase photochemical formation of hydrogen peroxide in authentic cloud waters, J. Geophys. Res., 99, 8231-8248, 1994.

Braun, W., Herron, J. T., and Kahaner, D. K.: Acuchem: A computer program for modeling complex chemical reaction systems, Int. J. Chem. Kin., 20, 51-62, 1988.

Chu, L. and Anastasio, C.: Formation of hydroxyl radical from the photolysis of frozen hydrogen peroxide, J. Phys. Chem. A, 109, 6264-6271, 2005.

Donati, A.: Spectroscopic and kinetic investigations of halogencontaining radicals in the tropospheric aqueous phase, $\mathrm{Ph}$.D. Dissertation, University of Leipzig, 2002.
Ershov, B. G.: Kinetics, mechanism and intermediates of some radiation-induced reactions in aqueous solutions, Russian Chem. Rev., 73, 101-113, 2004.

Matthew, B. M.: Chemical probe technique for the detection of oxidized halogen species in aqueous solution, Ph.D. Dissertation, University of California - Davis, 2002.

Matthew, B. M. and Anastasio, C.: Determination of halogenated mono-alcohols and diols in water by gas chromatography with electron-capture detection, J. Chromatogr. A, 866, 65-77, 2000.

Matthew, B. M. and Anastasio, C.: A chemical probe technique for the determination of reactive halogen species in aqueous solution: Part 1 - Bromide solutions, Atmos. Chem. Phys., 6, 24232437, 2006, http://www.atmos-chem-phys.net/6/2423/2006/.

Matthew, B. M., George, I., and Anastasio, C.: Hydroperoxyl radical $\left(\mathrm{HO}_{2}\right)$ oxidizes dibromide radical anion $\left(\mathrm{Br}_{2}-\right)$ to bromine $\left(\mathrm{Br}_{2}\right)$ in aqueous solutions: Implications for the formation of $\mathrm{Br}_{2}$ in the marine boundary layer, Geophys. Res. Lett., 30, 22972301, 2003.

Newberg, J. T.: Measurements of inorganic ion composition, UVvisible absorption and hydroxyl radical kinetics in marine particles from the northeasetrn Pacific Ocean, M. S. Thesis, University of California - Davis, 2003.

Zafiriou, O. C., True, M. B., and Hayon, E.: Consequences of $\mathrm{OH}$ radical reaction in sea water: Formation and decay of $\mathrm{Br}_{2}$ - ion radical, in: Photochemistry of Environmental Aquatic Systems, edited by: Zika, R. G. and Cooper, W. J., American Chemical Society, Washington D.C., 89-105, 1987.

Zhou, X. and Mopper, K.: Determination of photochemically produced hydroxyl radicals in seawater and freshwater, Mar. Chem., 30, 71-88, 1990. 